\title{
Chemical Ignition Characteristics of Ethanol Blending with Primary Reference Fuels
}

E. Singh ${ }^{1 *}$, E-A. Tingas ${ }^{1,4}$, D. Goussis ${ }^{2,3}$, H.G. $\operatorname{Im}^{1}$, S.M. Sarathy ${ }^{1 *}$

1. King Abdullah University of Science and Technology, Clean Combustion Research Center, Thuwal 23955-6900, Saudi Arabia

2. Department of Mechanics, School of Applied Mathematics and Physical Sciences, National Technical University of Athens, 15780 Athens, Greece

3. Department of Mechanical Engineering, Khalifa University of Science, Technology and Research, 127788 Abu Dhabi, United Arab Emirates

4. Perth College, University of the Highlands and Islands (UHI), Crieff Rd, Perth PH1 2NX, UK

Corresponding authors: eshan.singh@kaust.edu.sa

$$
\text { mani.sarathy@kaust.edu.sa }
$$

\section{Abstract}

The synergistic octane blending behavior of ethanol with gasoline and its surrogates has been observed by many researchers. The non-linear octane boosting tendency is observed at mid and high molar blends of ethanol in primary references fuels. The present work aims to provide chemical insight into this non-linear blending behavior of ignition processes when ethanol is blended with primary reference fuels. To this end, ignition delay time calculations, using a wellvalidated mechanism, were performed for several fuel blends of iso-octane, $n$-heptane, and ethanol. Temperature and pressure values were found, correlating experimentally measured octane numbers and simulated homogenous batch reactor ignition delay times. The temperature and pressure conditions obtained, were then used to study the evolution of heat release and reactivity before the onset of auto-ignition in a homogeneous premixed reactor. Markers of low and high temperature reactivity $\left(\mathrm{OH}\right.$ and $\mathrm{HO}_{2}$ ) were analyzed for various molar blends of $n$-heptane with ethanol/iso-octane. Ethanol was observed to be better at radical scavenging than iso-octane at higher mole fraction. A computational singular perturbation analysis was conducted for a selection of blends to clarify the reactions responsible for the synergistic blending behavior of ethanol in $\mathrm{n}$ heptane. The role of the $\mathrm{H}$-abstraction reactions was highlighted during the first ignition stage; reactions related to $\mathrm{n}$-heptane were found to compete with the $\mathrm{H}$-abstraction reactions of iso-octane or ethanol. Notably, the H-abstraction path of ethanol was more favored than that of the iso-octane, as a result of the smaller activation energies of the related reactions in the ethanol. The competition of the $\mathrm{H}$-abstraction paths resulted in a smaller radical pool in the $n$-heptane-iso-octane-air case, and an even smaller pool in the $n$-heptane-ethanol-air. In all the cases considered, the second stage was dominated mainly by hydrogen-related reactions, regardless of the initial mixture, with the $\mathrm{H}_{2} \mathrm{O}_{2}(+\mathrm{M}) \rightarrow 2 \mathrm{OH}(+\mathrm{M})$ and $\mathrm{H}+\mathrm{O}_{2} \rightarrow \mathrm{O}+\mathrm{OH}$ playing the most important roles. This work employed a novel approach to examine specific reactions responsible for auto-ignition in ethanol blends, which can be used for fuel design, primarily around the generation/consumption of radical pool intermediates by interaction with fuel components.

Keywords: biofuel, ethanol, engine knock, computational singular perturbation, kinetics

\section{Introduction}

In recent years, legislation on carbon dioxide $\left(\mathrm{CO}_{2}\right)$ emissions from the transportation sector has become more stringent. The transport sector contributes $14 \%$ of global $\mathrm{CO}_{2}$ emissions, $74 \%$ of which is generated by road transport alone [1]. Several ways to meet the $\mathrm{CO}_{2}$ targets include increasing engine efficiency and using fuels with a higher $\mathrm{H} / \mathrm{C}$ ratio (like methane), or bio-derived fuels. Bio-derived fuels (or biofuels) show low net $\mathrm{CO}_{2}$ emissions because the $\mathrm{CO}_{2}$ emitted by 
biofuels during the combustion process is consumed by the plant from which the biofuel is derived. One widely used biofuel--ethanol--is used in blends ranging from 5 to $85 \%$ (v/v) in gasoline for use in spark-ignited (SI) engines. Apart from reducing $\mathrm{CO}_{2}$ emissions by nature of being a biofuel, ethanol has a higher resistance to engine knock, improving the efficiency of SI engines. Because of its high research octane number (RON) [2] ethanol produces high engine efficiency in sparkignited engines; its high octane-sensitivity also offers good performance in modern high efficiency turbocharged SI engines [3, 4], thereby enabling lower net $\mathrm{CO}_{2}$ emissions.

Ethanol is known to boost the octane number of a base-fuel non-linearly [5-7]. A synergistic effect of ethanol addition to gasoline is that the RON of the mixture is higher than that suggested by linearly interpolating RON values of base-fuel and pure ethanol. Researchers have also recently observed similar synergistic behavior for other biofuels, like furans [8, 9] and prenol [10]. The extent of non-linearity is known to vary with the composition of the base-fuel. While ethanol shows synergistic blending behavior with primary reference fuels (PRFs) and commercial gasoline, an antagonistic behavior is observed when blending ethanol in toluene [11]. Similar antagonistic behavior has also been observed for methyl acetate [12]. Foong et al. [11] reported that nonlinearity was reduced when scaled on a molar basis, because ethanol--being a lighter molecule-has a large mole fraction for a given mass fraction [13-18]. Recently, Waqas et al. studied the blending effect of ethanol addition with several base-fuels and found synergistic blending boosting behavior when operating a CFR engine in SI--as well as in the HCCI mode--in terms of the blending octane number (BON) [7, 19]. High BON has been attributed to the radical scavenging nature of ethanol [2], which was validated by a reduction in $\mathrm{OH}$ and $\mathrm{HO}_{2}$ radicals in the low temperature chemistry region [2]. However, details about the specific reactions responsible for suppressing reactivity have not been investigated. The purpose of this work is to provide additional insight into the non-linear blending characteristics of ethanol with alkane fuels, like n-heptane and iso-octane.

Engine knock is governed by auto-ignition of the fuel/air mixture. Understanding the fundamental ignition characteristics of fuel/air mixtures can help clarify the role of ethanol in preventing engine knock [20]. This work assumes a correlation between gas-phase ignition delay time and octane numbers measured in engines. This assumption is based on engine experiments conducted in HCCI mode [21, 22], as well as shock tube experiments [23, 24], where a direct link between the octane number of fuel and its auto-ignition delay time has been observed. Studies show a high correlation between the auto-ignition tendency in HCCI mode to the knocking tendency in the SI mode of engine operation. In an SI engine, the end-gas ahead of the spark-initiated flame front becomes heated and compressed before auto-igniting, leading to pressure oscillations, and known as engine knock. Fundamentally the two phenomena--engine knock and auto-ignition in a homogenous environment--are similar, and researchers have attempted to relate octane number to the ignition delay time (IDT) in the negative temperature coefficient (NTC) region. Mehl et al. correlated the antiknock index (AKI) with the IDT, calculated at an initial pressure $\left(\mathrm{p}_{\mathrm{o}}\right)$ of 25 bar and initial temperature $\left(\mathrm{T}_{\mathrm{o}}\right)$ of $825 \mathrm{~K}$ [25]. Sarathy et al. proposed that the RON of PRFs can be correlated with IDT calculated at $\mathrm{p}_{\mathrm{o}}$ of $20 \mathrm{~atm}$ and $\mathrm{T}_{\mathrm{o}}$ of $835 \mathrm{~K}$ [26]. Badra et al. further expanded the correlation for toluene reference fuel (TRF), and toluene primary reference fuels (TPRF) [27] with $\mathrm{p}_{\mathrm{o}}$ of $50 \mathrm{~atm}$ and $\mathrm{T}_{\mathrm{o}}$ of $850 \mathrm{~K}$. Singh et al. utilized up to six components for their formulation, correlating RON and IDT with high regression, at $\mathrm{p}_{\mathrm{o}}$ of 25 bar $\mathrm{T}_{\mathrm{o}}$ of $750 \mathrm{~K}$ [4]. Westbrook et al. used experimentally obtained pressure data to find ignition delay times corresponding to RON and 
MON values of pure and compound mixtures [28, 29]. Correlating homogenous gas-phase IDT with RON has also been attempted for mixtures of ethanol with PRFs, previously [30].

The goal of the present work is to fill the gaps in the current understanding of ethanol's antiknock quality in blends by examining specific reactions responsible for auto-ignition suppression with ethanol addition. To this end, computational singular perturbation ((CSP), an algorithmic method of asymptotic analysis) has been utilized, which enables the systematic analysis of dynamic systems, unhindered by system size or complexity [31, 32]. It has been successfully employed in the analysis of a large variety of fuels [33-40] (e.g., $\mathrm{H}_{2}, \mathrm{CH}_{4}, \mathrm{DME}, \mathrm{C}_{2} \mathrm{H}_{5} \mathrm{OH}, n$-hexane, $n$-heptane, iso-octane) and a wide range of different combustion configurations (e.g., auto-ignition [41], laminar flames [42], counterflow flames [92], turbulent flames in the context of DNS [43] and RANS [39], triple-flames [44] and partially stirred reactors [45]). CSP algorithmic tools can help to identify the physical processes and components governing the evolution of a system, by examining the system's characteristic time scale [33]. Therefore, in the present study, tools generated in the CSP framework were used to identify: (i) reactions with the greatest contribution to the system's characteristic time scale, and thus, to the system's ignition delay time [46, 47], and (ii) the species' mass fractions most related to the characteristic CSP mode $[36,39]$ of the system.

The effect of ethanol addition to $n$-heptane, and its effect on low temperature chemistry suppression, is investigated and compared to iso-octane addition to $n$-heptane. Initially, octane number values were taken from [11], and the kinetic model was tested for various PRFs and other fuel blends with known octane values. A high regression valued fit between the octane number values and ignition delay times was obtained at a particular combination of temperatures and pressures. This temperature and pressure condition was chosen for subsequent analysis, in which the reactions leading to ignition were analyzed using CSP for $n$-heptane and its molar blends with iso-octane and ethanol.

\section{Methodology}

The present work investigates the reactions setting off auto-ignition in mixtures of $n$-heptane (PRF0) with ethanol and iso-octane (PRF100). Low temperature reactions are critical to ignition of the mixtures studied in this work [2]. RON values of blends of $n$-heptane-iso-octane-ethanol were obtained from the literature [11]. The details of the experimental methodology for measuring octane numbers can be found in [11].

Ignition delay times for $n$-heptane-iso-octane-ethanol blends were calculated based on the mechanism proposed by Sarathy et al. [48]. The chemical kinetics mechanism employed consisted of $\mathrm{N}=2406$ species, $\mathrm{E}=6$ elements $(\mathrm{O}, \mathrm{H}, \mathrm{C}, \mathrm{N}, \mathrm{Ar}$ and $\mathrm{He})$ and $\mathrm{K}=9633$ elementary reactions [48]. The mechanism was developed by LLNL-KAUST-NUIG as part of a study of gasoline surrogates. This hierarchical mechanism was built to complement previously validated submechanisms for ethanol, n-heptane, and iso-octane. Variants of the gasoline surrogates' mechanism have been validated and used previously in engine studies on ethanol and PRFs [4952].

The criterion for ignition delay was taken as the time corresponding to the maximum slope of temperature versus the time curve. In the case of multiple values of occurrences of the maximum (local) slope (common for fuels with two-stage ignition characteristics), the latest value was chosen, which represented the high-temperature ignition. The ignition delay was calculated for temperatures ranging from $700 \mathrm{~K}$ to $1100 \mathrm{~K}$ (in a step of $25 \mathrm{~K}$ ) and pressure from 20 bar to 40 bar 
(in a step of 5 bar), totaling 4505 simulations [17(temp)x5(pres)x53(blends)]. These simulations provided the temperature-pressure conditions in a homogeneous batch reactor which correlated best with the knock tendency of fuels in the RON tests. The highest regression coefficient $\left(\mathrm{R}^{2} \sim 0.8\right.$, adjusted $\mathrm{R}^{2} \sim 0.79$ ) between known RON values and calculated IDT was obtained for $\mathrm{T}=750 \mathrm{~K}$ and $\mathrm{P}=40$ bar. The T-P values were similar to those suggested in previous literature $[4,27]$. The endgas ahead of the flame front was compressed and heated; this T-P was representative of the endgas before auto-ignition. Experiments from Szybist et al. showed unburnt mixture temperatures in this range for RON tests, depending on the compression ratio of the engine [53]. A relatively lower temperature (compared to previous publications), coincided with the higher pressure, placing the mixtures in the NTC region, where the RON of fuel blends has been correlated with IDT previously [25-27]. Details on the methodology following are given in the Supplementary Material.

The calculations of ignition delay time were carried out using the homogeneous batch reactor solver in CHEMKIN PRO [54]. The energy equation was solved at constant volume and an equivalence ratio of 1 , similar to $[26,27,55,56]$. The ignition delay time refers to the time required for a fuel-air mixture to auto-ignite at a given initial temperature-pressure. Once a temperaturepressure condition was fixed to represent octane behavior ( $\mathrm{T}=750 \mathrm{~K}$ and $\mathrm{P}=40$ bar), similar calculations were conducted for a range of PRFs and $n$-heptane-ethanol mixtures, ranging from 0 to $100 \%$ of ethanol (or iso-octane in the case of the PRF mixture), to observe the reactions during the evolution of ignition in a batch reactor. Important combustion markers (like $\mathrm{OH}, \mathrm{HO}_{2}$, and temperature) were analyzed, and a comparison is presented for $n$-heptane-iso-octane blend versus $n$-heptane-ethanol blends. The observations pointed to the disparity in the radical concentration $\left(\mathrm{OH}\right.$ and $\left.\mathrm{HO}_{2}\right)$ between the two tested blends. Specific reactions responsible for such observations were then investigated using a CSP tool.

The timescale participation index (TPI) determined the contribution of each reaction in the kinetics mechanism employed in the explosive timescale (the characteristic timescale of the system during ignition, and directly related to the ignition delay time of the process $[33,57])$. Therefore, reactions with the largest contributions were those with the greatest effect on the evolution of the process. This tool has been extensively used for the investigation of auto-ignition phenomena and flames in a wide range of fuels and initial conditions [33, 35, 41, 46, 47, 57]. Due to the expensive nature of the calculations involved, the analysis was limited to a small set of the blends. Specifically, three mixtures ( $\mathrm{mol} \%)$ were used:

- $n$-heptane $\left(\mathrm{nC}_{7} \mathrm{H}_{16}\right)$ - air

- $60 \% n-\mathrm{C}_{7} \mathrm{H}_{16}-40 \% i \mathrm{C}_{8} \mathrm{H}_{18}-$ air

- $60 \% n-\mathrm{C}_{7} \mathrm{H}_{16}-40 \% \mathrm{C}_{2} \mathrm{H}_{5} \mathrm{OH}-$ air

Previous works have detailed the methodology for CSP analysis, and further details on the methodology used are provided in the Supplementary Material [35-37, 39, 41, 57].

\section{Results and discussions:}

\section{Effect of ethanol addition on RON}

Traditionally, correlating RON values of ethanol blends with their corresponding ignition delay values has resulted in significant error [58]. A few key differences exist in the measured RON and calculated IDTs. Homogeneous ignition delay simulations assume a premixed, fully homogenous gas phase reaction; however, in engine experiments, physical effects may be significant when considering ethanol blends, due to the high latent heat of vaporization of ethanol [59]. Hence, 
experimental octane measurements are not entirely representative of the chemical auto-ignition suppression. An intake temperature as high as $110{ }^{\circ} \mathrm{C}$ is needed to maintain a similar charge temperature in RON and MON tests when using ethanol [60].

Engine knock is the auto-ignition of end gas, ahead of the flame front. Because of similar values in the flame speed for most hydrocarbons (and hence PRFs), this effect can generally be offset by a common value [61]. However, ethanol shows relatively higher laminar flame speed [62]. This translates to a greater effect of flame travel, further complicating determination of the octane number of ethanol blended fuels from ignition delay time data alone. However, the significance of flame speed is minor compared to that of the auto-ignition phenomenon. Moreover, residual incylinder NO affects the flame speed and auto-ignition properties of the charge, and NO concentrations are also different using an oxygenated molecule (i.e., ethanol) [63]. The complex interactions leading to auto-ignition in an engine are beyond the scope of this work, and focus here will be on the chemical kinetic aspect of auto-ignition, thereby isolating the chemical effect of ethanol addition on reactivity. The methodology following in the current work ensures that chemical effects are investigated and their contribution to octane enhancement in an engine ascertained.

RON and MON ratings linearly scale with a volumetric blend of $n$-heptane (0) in iso-octane (100). Similar molecular weights $(100.21 \mathrm{~g} / \mathrm{mol}$ for $n$-heptane and $114.23 \mathrm{~g} / \mathrm{mol}$ for iso-octane) cause the two molecules to exhibit almost linear behavior octane rating by mol.\%. However, due to a relatively low molecular weight $(46.07 \mathrm{~g} / \mathrm{mol})$, ethanol's vol. $\%$ and mol.\% addition show marked differences. Several researchers have noted suppressed non-linearity in octane boosting by ethanol when considered on a mole basis $[11,64]$. These observations are valid for lower blends of ethanol. Figure 1 shows the comparison between linear-by-mole values (dashed yellow lines) and the experimentally observed RON values (solid shapes, taken from [11]) for a mixture of PRFs and ethanol. Synergistic behavior can be observed for an ethanol-PRF blend at a high mole fraction of ethanol. Chemical reaction rates scale with the mole fraction; so, investigating mid and higher blends of ethanol in $n$-heptane will reveal the chemical pathways responsible for the suppression of reactivity by ethanol.

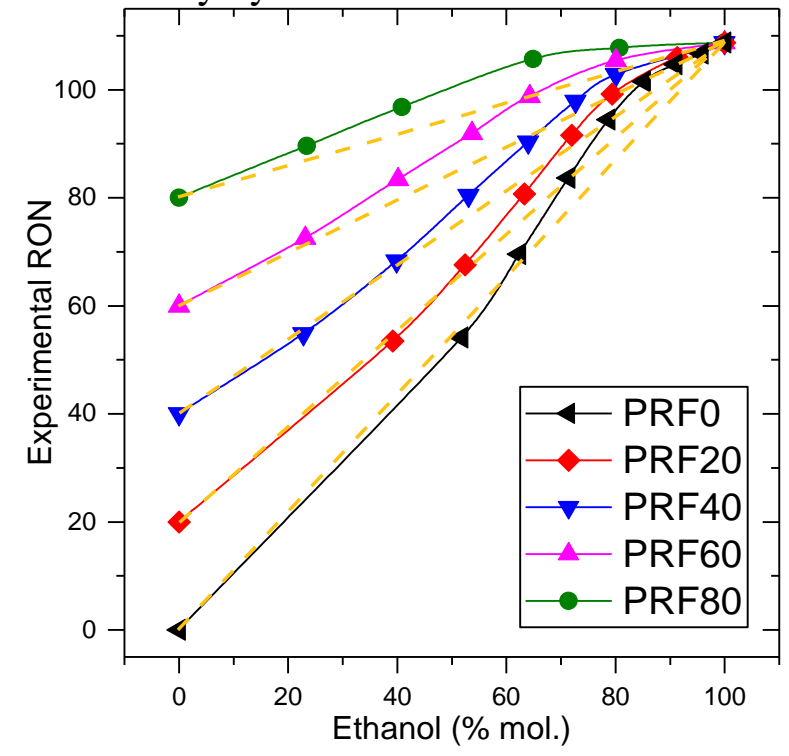


Figure 1: RON of ethanol added to PRFs [11]. Linear-by-mole line is yellow dashed lines for each PRF-ethanol mixture. Nonlinearity in octane boosting tendency suppressed and delayed (in terms of \% additive) when plotted on mole fraction of ethanol in PRF.

Unlike ethanol, iso-octane does not suppress low temperature chemistry. Comparing ethanol and iso-octane permits the investigation of low temperature chemistry suppression exhibited by ethanol. Figure 2 shows RON values for ethanol-PRF mixtures, relative to the same mole fraction of iso-octane added to the corresponding PRF mixture. The dashed lines are all PRFs, but are represented in terms of iso-octane added to a certain base PRF. Ethanol shows higher octane rating for all cases relative to the similar mole fraction of iso-octane in PRF. For PRF0 (or pure $n$ heptane), RON values are available for ethanol mole fraction of 50\% and above. The octane boosting tendency of ethanol in PRF0 is greater than that of iso-octane at mid to high blends of ethanol in $n$-heptane. In the following section, the homogenous batch reactor simulations conducted explain this disparity between the effectiveness of ethanol and iso-octane. The following section considers addition of iso-octane or ethanol in PRF0 (shown in thicker lines in Fig. 2.

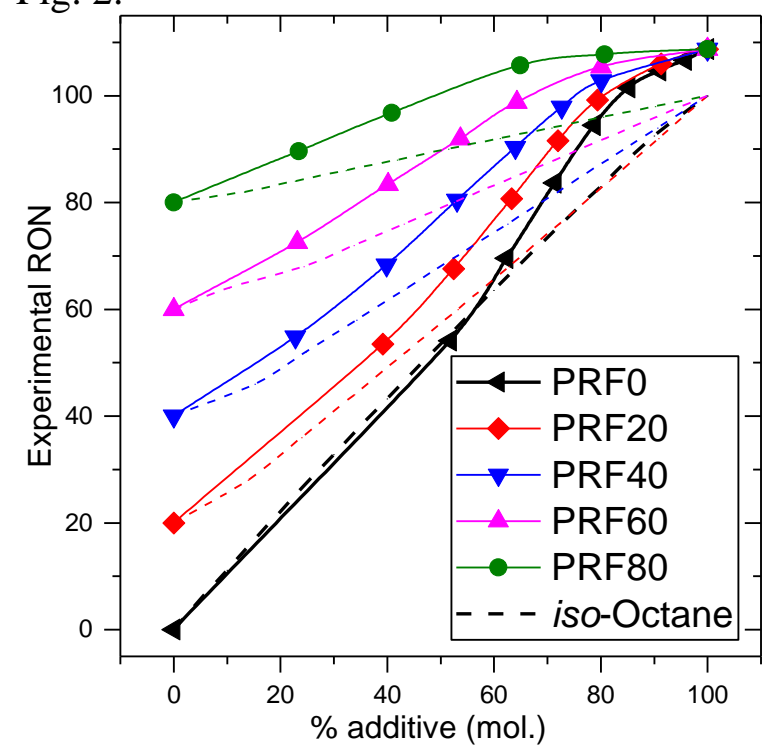

Figure 2: Comparison of experimental RON values for ethanol-PRF and iso-octane-PRF blends. Solid symbols represent ethanolPRF; dashed lines represent iso-octane-PRF mixtures. Non-linear octane boosting tendency is observed at mid and high blends of ethanol-PRF.

\section{Homogeneous batch reactor simulations}

The evolution of various parameters leading to ignition was investigated for varying molar blends of $n$-heptane and ethanol/iso-octane under the same conditions as [65-67]. Temperature, heat release rates, and radicals $\left(\mathrm{OH}\right.$ and $\left.\mathrm{HO}_{2}\right)$ are plotted for pure $n$-heptane and a selected few mixtures of ethanol/iso-octane in $n$-heptane in Figs. 3-6 [68]. Similar calculations were made for additives ranging from 0 to $90 \%$ (mol. \%) in $n$-heptane and can be found in the Supplementary Material (Appendix 2). Two-stage ignition delay was observed for most of the blends. The first stage heat release was caused by low temperature chemistry (LTC) reactions. Low temperature heat release increased the temperature, which accelerated the transition to high temperature reactions.

Long chain alkanes ( $n$-heptane in this case) readily underwent $\mathrm{R}+\mathrm{O}_{2}=\mathrm{RO}_{2}$, oxygen addition at low temperatures. Isomerization of $\mathrm{RO}_{2}$ occurred where an $\mathrm{H}$-atom migrated from alkyl site to the peroxy site. A five-, six-, or seven-membered ring structure intermediate formed a hydro-peroxy radical $(\mathrm{QOOH})$. After that, a second $\mathrm{O}_{2}$ addition to $\mathrm{QOOH}$ led to formation of ketohydroperoxides 
(KHP), which dissociated to yield $\mathrm{OH}$ radicals. $\mathrm{OH}$ concentration was monitored in the present work, as a reflection of reactivity in the low temperature region. Alternatively, QOOH may form cyclic ethers and $\mathrm{OH}$ radicals or undergo $\beta$-scission to form olefins. The rate of formation of cyclic ethers was shown to be dependent on the branching of the molecule [69-72]. For a highly branched molecule, the pathway leading to formation of KHP was kinetically less favored due to the decreased number of secondary $\mathrm{C}$ sites. Therefore, in the context of the present study, formation of cyclic ether was preferred in the case of iso-octane, when compared to $n$-heptane [73]. Wang et. al. also observed third $\mathrm{O}_{2}$ addition, leading to formation of keto-dihydroperoxides and/or ketohydroperoxy cyclic ethers [74]. The heat release accompanying low temperature reactions increased the global temperature, making $\mathrm{O}_{2}$ addition less responsive. This led to high temperature chemistry after a hiatus of the intermediate negative temperature region, in which reactivity reduced, although the temperature increased. Further details of the process have been well documented by several authors [51, 74-77].

Low temperature chemistry is suppressed with the addition of octane boosting additives. However, the degree of suppression is not the same with the addition of ethanol and iso-octane. Reduction in low temperature chemistry from Figs. 3-6 was expected, as $n$-heptane is the longest chain hydrocarbon in the mix. A lower $n$-heptane concentration in the mixture proportionally reduced the low temperature reactivity. The radical pool (signified by $\mathrm{OH}$ and $\mathrm{HO}_{2}$ ) closely followed the heat release rate, showing a maximum in the LTHR region. Differences in maximum LTHR were observed at 40 (mol.) \% addition of additives and beyond; and ethanol showed higher LTHR suppression compared to iso-octane (Fig. 5). It can also be observed that ethanol--a known radical scavenger--showed no LTHR at $80 \%$ or higher blend in $n$-heptane (Fig. 6).

A summary of the computational results is provided in Fig. 7, which shows the maximum values of select parameters in the LTC region. As LTC was completely suppressed for ethanol- $n$-heptane mixtures of $80 \%$ and above, the plots were limited to $70 \%$ additive concentration (on the $\mathrm{x}$-axis). It can be observed in Fig. 7a that the heat release rates were similar for the addition of iso-octane and ethanol at low mole fraction blends; and low temperature heat release was suppressed more for ethanol addition than iso-octane at mole fraction $40 \%$ and more. This agrees well with the measured RON deviation from experiments, shown in Fig. 2 (solid black symbols and black dashed line), signifying the importance of low temperature chemistry in controlling the overall reactivity, which in turn effects the RON measured experimentally. Figures. 7b and 7c show the maximum $\mathrm{OH}, \mathrm{HO}_{2}$ mole fraction in the LTC region. Although the heat release rates were similar, ethanol- $n$-heptane blends showed lower reactivity than $i$ so-octane- $n$-heptane blends, as seen by the reduced $\mathrm{OH}$ mole fraction with the addition of ethanol in $n$-heptane (Fig. $7 \mathrm{~b}$ ). $\mathrm{HO}_{2}$, however, is greater for ethanol addition, compared to iso-octane addition in all blend ratios (Fig. 7c). This can be attributed to the formation of the alphahydroxyethyl radical, which reacts with $\mathrm{O}_{2}$ to form $\mathrm{HO}_{2}$. Hence, this reaction was favored with ethanol, leading to higher $\mathrm{HO}_{2}$ formation and larger peaks in LTC region. This is confirmed in the detailed computational analysis that follows. 


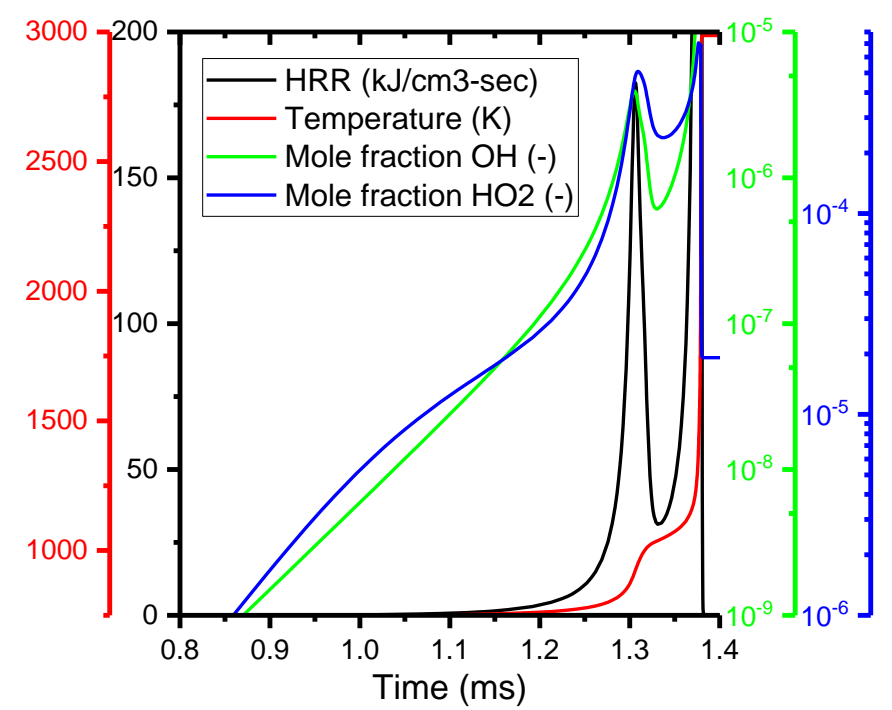

Figure 3: Evolution of heat release rate, temperature, $\mathrm{OH}$, and $\mathrm{HO}_{2}$ for pure $n$-heptane at initial conditions of $750 \mathrm{~K}$ and 40 bar.

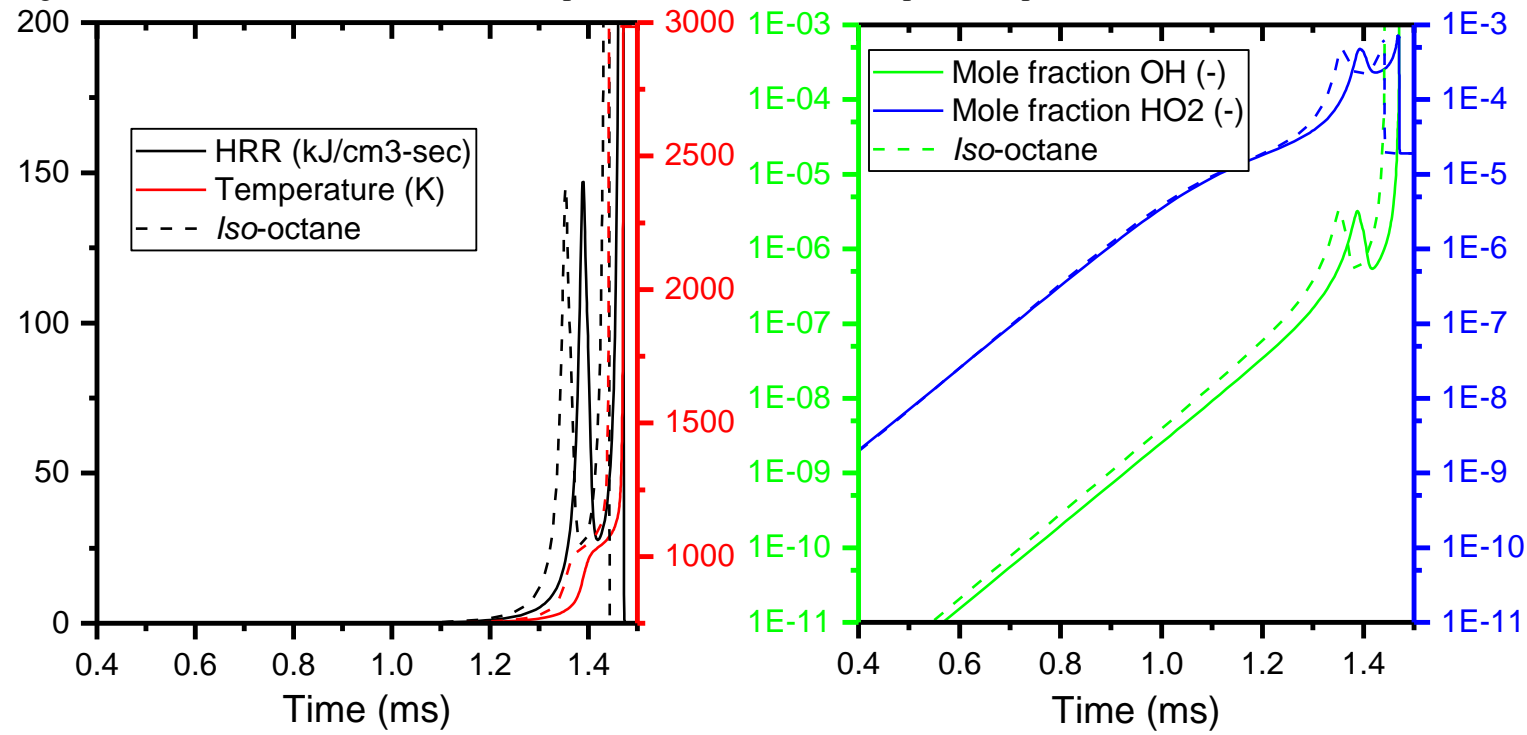

Figure 4: Evolution of heat release rate (HRR), temperature, $\mathrm{OH}$, and $\mathrm{HO}_{2}$ for a mixture of $90 \% n$-heptane and $10 \%$ isooctane/ethanol (a) heat release rate and temperature, (b) mole fraction of $\mathrm{OH}$ and $\mathrm{HO}_{2}$. Values for ethanol- $n$-heptane are solid lines; iso-octane- $n$-heptane mixture are dashed lines. 

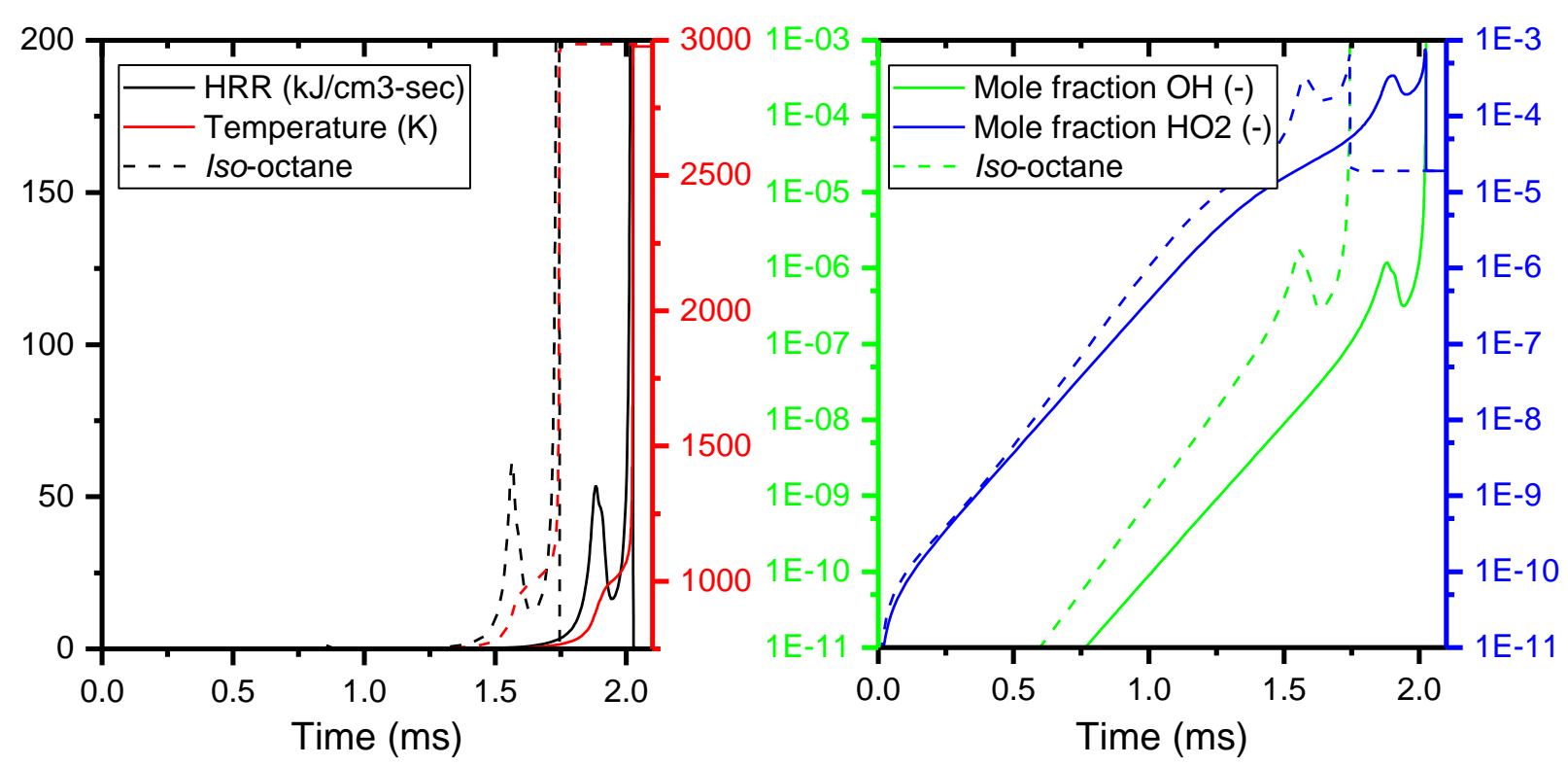

Figure 5: Evolution of heat release rate (HRR), temperature, $\mathrm{OH}$, and $\mathrm{HO}_{2}$ for mixture of $60 \% n$-heptane and $40 \%$ isooctane/ethanol. (a) heat release rate and temperature, (b) mole fraction of $\mathrm{OH}$ and $\mathrm{HO}_{2}$. Values for ethanol- $n$-heptane are solid lines; iso-octane- $n$-heptane mixture are dashed lines.
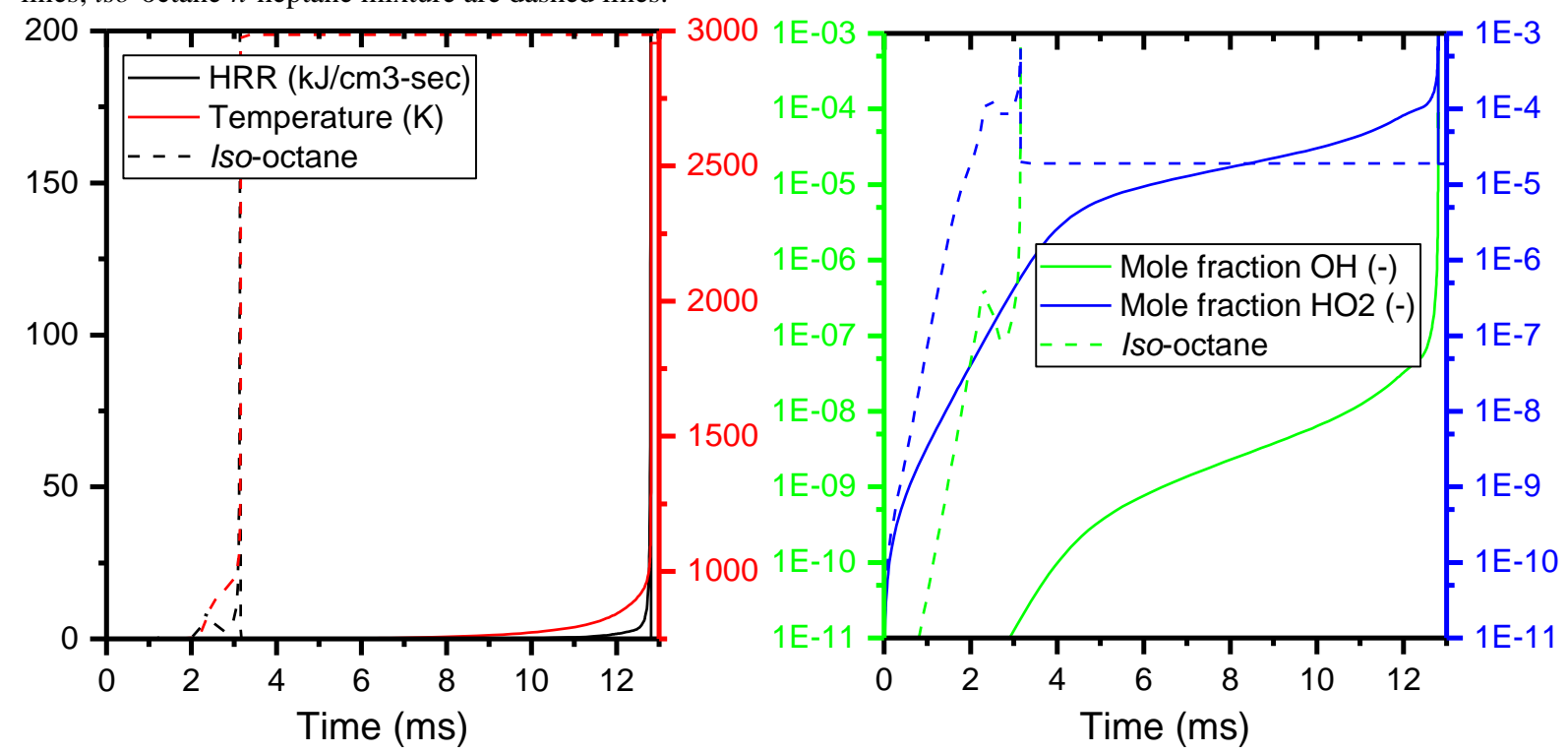

Figure 6: Evolution of heat release rate (HRR), temperature, $\mathrm{OH}$, and $\mathrm{HO}_{2}$ for mixture of $20 \% n$-heptane and $80 \%$ isooctane/ethanol. (a) heat release rate and temperature, (b) mole fraction of $\mathrm{OH}$ and $\mathrm{HO}_{2}$. Values for ethanol- $n$-heptane are solid lines; iso-octane- $n$-heptane mixture are dashed lines. 

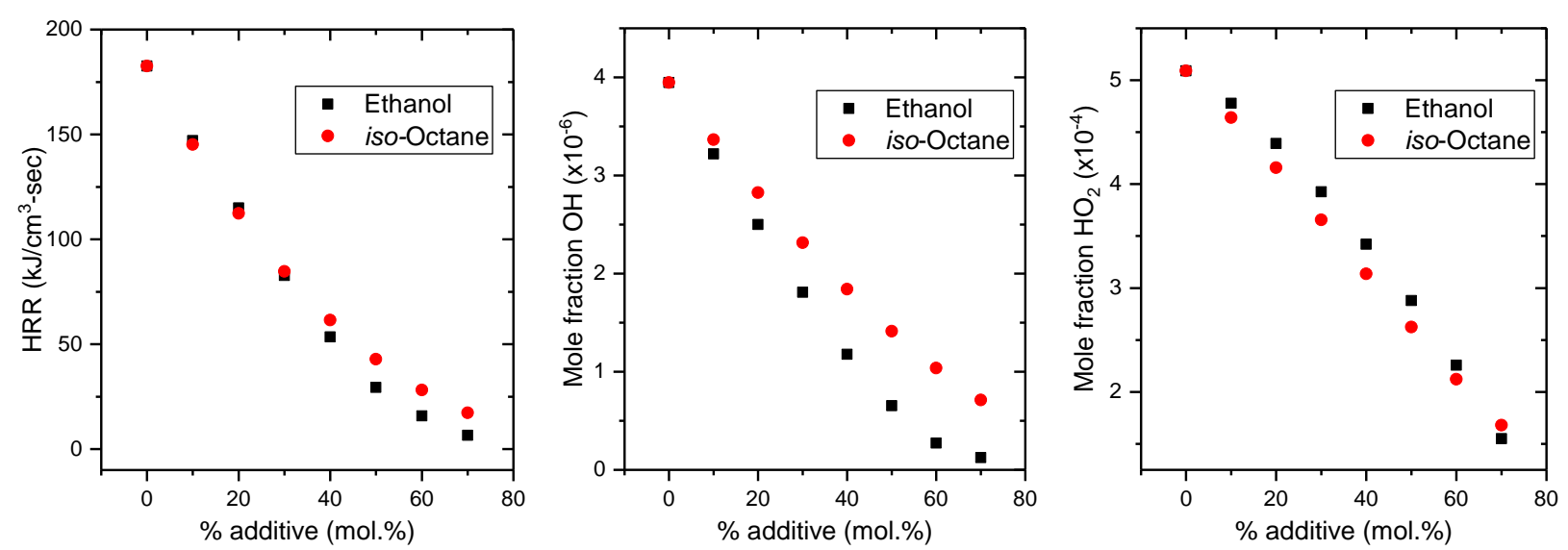

Figure 7: a) Maximum heat release rate, b) maximum $\mathrm{OH}$ mole fraction, c) maximum $\mathrm{HO}_{2}$ mole fraction in low temperature region.

Non-linear behavior of the octane boosting tendency was observed at high molar concentrations of ethanol in $n$-heptane. Chemical kinetic analysis showed that ethanol suppressed LTHR more effectively than iso-octane, at $40 \%$ (mol.) addition and above, which agrees with the experimentally observed octane boosting tendency. In this regard, three mixtures, pure $n$-heptane and $40 \%$ (mol.) octane additive (iso-octane/ethanol) in $n$-heptane, were chosen for subsequent CSP analysis.

\section{Computational singular perturbation calculations}

Timescales that characterize the dynamics of the three processes are displayed in Fig. 8. As shown, in each case, all of the timescales are of a dissipative nature (represented by black lines), excepting two (red lines): a fast and a slow explosive timescale. Both explosive timescales exist for most of the process. Very close to the end of the process, they both disappear and re-appear shortly afterward before they merge and disappear again. As will be shown later, the time of their first disappearance signified the first stage of the ignition process, and their second disappearance coincided with the second stage of the ignition process. The period from the start of the process to the time when the explosive timescales disappeared for the second time is the explosive stage, and its general features have been extensively reported in the literature $[33,35,36,41,46,47,57,78$, 79]. The following analysis concentrates on the fastest of the explosive timescales, say $\tau_{e, f}$, which is characteristic of the dynamics in both ignition stages. In particular $\tau_{e, f}$ sets the time frame of the action of the CSP mode $\boldsymbol{a}_{e, f} f^{e, f}$, where $\boldsymbol{a}_{e, f}$ and $f^{e, f}$ the eigenvector and the amplitude related to the fast explosive mode.
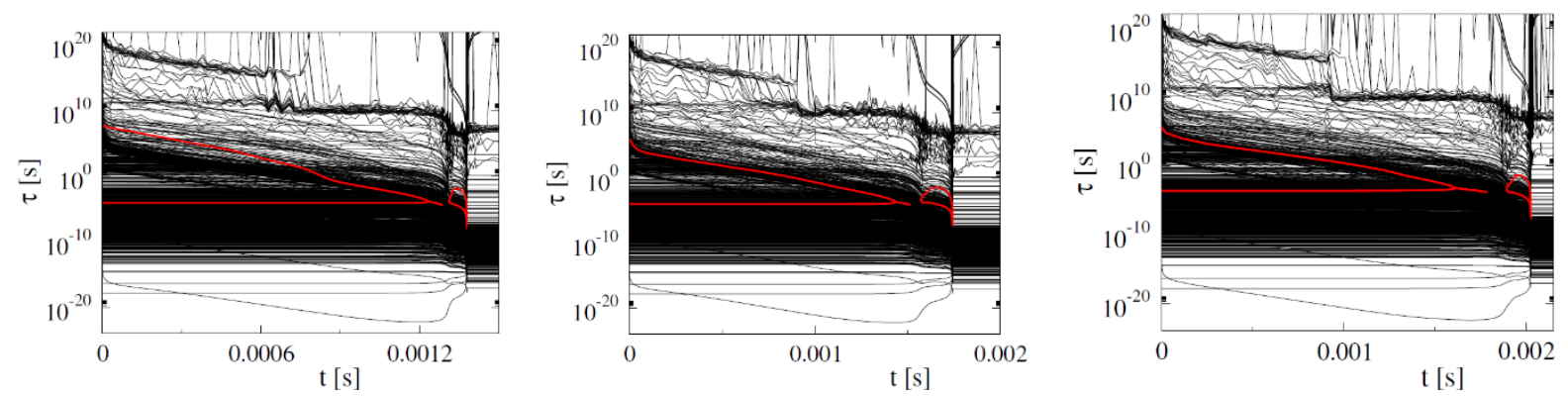

Figure 8: Developing time scales during auto-ignition of $n$-heptane/air (left), $60 \% n$-heptane and $40 \%$ iso-octane (middle) and $60 \%$ $n$-heptane and $40 \%$ ethanol (right) mixtures. Solid black and red lines represent dissipative and explosive modes, respectively; $\mathrm{T}_{\mathrm{o}}=750 \mathrm{~K}, \mathrm{P}_{\mathrm{o}}=40$ bar. 
As seen in Fig. 8, in all three cases, $\tau_{e, f}$ was in the middle of a dense area of dissipative time scales and no time scale gap developed between $\tau_{e, f}$ and the fastest dissipative time scales. If the system generating these features were fully non-linear, the consideration of $\tau_{e, f}$ would be meaningless. However, the constancy of many of the fastest time scales (among them $\tau_{e, f}$ ), during the largest part of the explosive stage, suggests that the prevailing dynamics were quasilinear. In such a case, investigation of the reactions generating $\tau_{e, f}$ was legitimate, as it was established in the existing literature related to the autoignition dynamics of DME/air, EtOH/air and $n$-Hexane/air mixtures $[37,41]$.
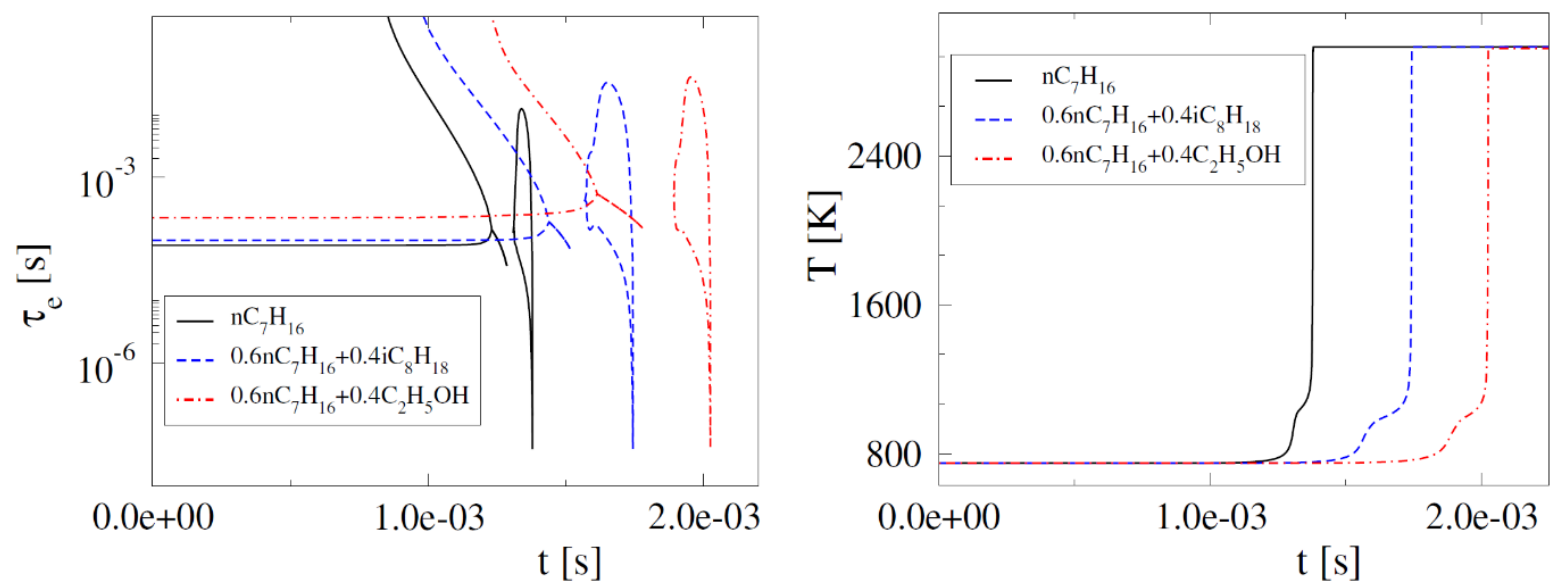

Figure 9: Developing explosive time scales (left) and temperature (right) evolution during autoignition of $n$-heptane/air, $60 \% n$ heptane and $40 \%$ iso-octane and $60 \% n$-heptane and $40 \%$ ethanol mixtures; $\mathrm{T}_{0}=750 \mathrm{~K}, \mathrm{P}_{\mathrm{o}}=40$ bar.

Figure 9 displays the temperature evolution, along with the evolution of the fast, explosive timescale $\tau_{e, f}$ for the three cases under investigation. Temperature profiles show: (i) the $n$ heptane/air case ignited faster than the others and the addition of iso-octane led to shorter ignition delay time than the ethanol addition; (ii) all three cases were characterized by two-stage ignition; (iii) the rate of temperature increase during the first-stage was greatest in the $n$-heptane/air case and least for the addition of ethanol; (iv) all three mixtures reached the same final temperature; (iv) all three mixtures entered the second ignition stage at the same temperature $(\sim 1180 \mathrm{~K})$. These observations suggest that the first ignition stage played a significant role in the determination of ignition delay time of the mixtures. As will be shown later, this was also confirmed by the results from the CSP diagnostics. Additionally, the profiles of explosive timescales in Fig. 9 show that during the first stage ignition, the $\tau_{e, f}$ in the $n$-heptane/air case was always smaller than the $\tau_{e, f}$ in the other two cases, while during the second ignition stage all three mixtures seemed to exhibit similar $\tau_{e, f}$. Also, as Fig. 10 illustrates, the steep temperature rise in both ignition stages (in all three cases) coincided with the disappearance of the explosive timescales.
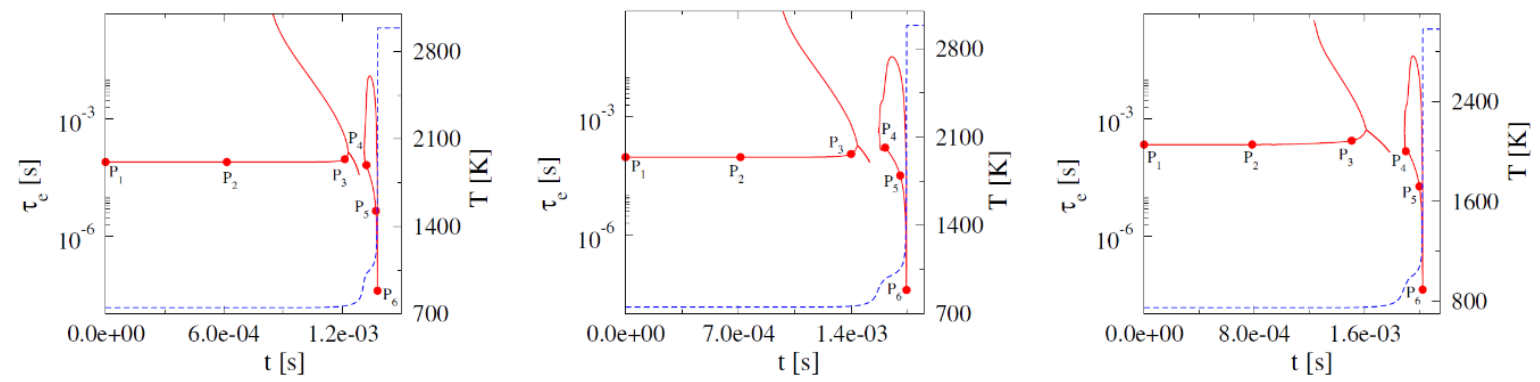
Figure 10: Developing explosive time scales and temperature evolution during autoignition of $n$-heptane/air (left), $60 \% n$-heptane and $40 \%$ iso-octane blend (middle) and 60\% $n$-heptane and $40 \%$ ethanol (right) mixtures. Points represent selected points in Tables 1 and $2 ; \mathrm{T}_{\mathrm{o}}=750 \mathrm{~K}, \mathrm{P}_{\mathrm{o}}=40$ bar.

To investigate the reactions that contributed to the generation of $\tau_{e, f}$ in the three cases under examination, representative points in time along the explosive stage were selected and the TPI values of the $\tau_{e, f}$ calculated for all three cases. The selected points are displayed in Fig. 10; the list with the most significant reactions in terms of TPI values, is shown in Table 1.

Table 1: Reaction groups with significant contribution to fast time scale $\tau_{e, f}$ generation during autoignition of $n$-heptane/air mixture; F: nC7H16, R: C7H15, Q: C7H14, Q': C7H13 for $n$-heptane (reaction groups $\mathrm{R}^{3 \mathrm{xxx}}$ ) and iso-octane (reaction groups $\mathrm{R}^{6 \mathrm{xxx}}$ ).

$\begin{array}{ll}\text { 1f } & \mathrm{H}+\mathrm{O}_{2} \rightarrow \mathrm{O}+\mathrm{OH} \\ 3 f & \mathrm{OH}+\mathrm{H}_{2} \rightarrow \mathrm{H}+\mathrm{H}_{2} \mathrm{O} \\ 3 \mathrm{~b} & \mathrm{OH}+\mathrm{H}_{2} \leftarrow \mathrm{H}+\mathrm{H}_{2} \mathrm{O} \\ 8 f & \mathrm{H}+\mathrm{OH}+\mathrm{M} \rightarrow \mathrm{H}_{2} \mathrm{O}+\mathrm{M} \\ 12 \mathrm{f} & \mathrm{HO} 2+\mathrm{H} \rightarrow \mathrm{OH}+\mathrm{OH} \\ 15 \mathrm{f} & \mathrm{HO} 2+\mathrm{OH} \rightarrow \mathrm{H}_{2} \mathrm{O}+\mathrm{O}_{2} \\ 16 / 17 \mathrm{f} & \mathrm{HO}_{2}+\mathrm{HO} 2 \rightarrow \mathrm{H}_{2} \mathrm{O}_{2}+\mathrm{O}_{2} \\ 18 / 19 \mathrm{f} & \mathrm{H}_{2} \mathrm{O}_{2}(+\mathrm{M}) \rightarrow \mathrm{OH}+\mathrm{OH}(+\mathrm{M}) \\ 144 \mathrm{f} & \mathrm{CH}_{3}+\mathrm{HO}_{2} \rightarrow \mathrm{CH}_{3} \mathrm{O}+\mathrm{OH} \\ 302 \mathrm{f} & \mathrm{C}_{2} \mathrm{H}_{4}+\mathrm{OH} \rightarrow \mathrm{C}_{2} \mathrm{H}_{3}+\mathrm{H}_{2} \mathrm{O}\end{array}$

\section{$366 / 367 \mathrm{f} \quad \mathrm{C} 2 \mathrm{H} 5 \mathrm{OH}+\mathrm{OH} \rightarrow \mathrm{sC}_{2} \mathrm{H}_{4} \mathrm{OH} / \mathrm{pC} 2 \mathrm{H}_{4} \mathrm{OH}+\mathrm{H}_{2} \mathrm{O}$}

671f $\quad \mathrm{nC}_{3} \mathrm{H}_{7}+\mathrm{O}_{2} \rightarrow \mathrm{nC}_{3} \mathrm{H}_{7} \mathrm{O}_{2}$

$\mathrm{R} 3054 \mathrm{f} \quad \mathrm{F}+\mathrm{OH} \rightarrow \mathrm{R}+\mathrm{H}_{2} \mathrm{O}$

$\mathrm{R} 3058 \mathrm{f} \quad \mathrm{F}+\mathrm{HO}_{2} \rightarrow \mathrm{R}+\mathrm{H}_{2} \mathrm{O}_{2}$

$\mathrm{R} 3289 \mathrm{f} \quad \mathrm{RO} 2 \rightarrow \mathrm{Q}+\mathrm{HO}_{2}$

$\mathrm{R} 3295 \mathrm{R} \quad \mathrm{RO} 2 \rightarrow \mathrm{QOOH}$

$\mathrm{R} 3399 \mathrm{f} \quad \mathrm{O} 2 \mathrm{QOOH} \rightarrow \mathrm{KET}+\mathrm{OH}$

R3418f $\quad$ KET $\rightarrow$ products $+\mathrm{OH}$

$\mathrm{R} 6772 \mathrm{f} \quad \mathrm{F}+\mathrm{OH} \rightarrow \mathrm{R}+\mathrm{H}_{2} \mathrm{O}$

For the pure $n$-heptane case, Table 2 shows that at points $\mathrm{P} 1, \mathrm{P} 2$, and $\mathrm{P} 3$, along the first ignition stage, $\tau_{e, f}$ was mainly promoted by reaction group $\mathrm{R}^{3295 f}$, which led to the formation of hydroperoxy-alkyl radicals $(\mathrm{QOOH})$ through the isomerization of alkylperoxy radicals $\left(\mathrm{RO}_{2}\right)$. A significant contribution, favoring the explosive character of $\tau_{e, f}$, was also provided by reaction groups $\mathrm{R}^{3399 \mathrm{f}}$ and $\mathrm{R}^{3418 \mathrm{f}}$, the first leading to the formation of one molecule of the highly reactive $\mathrm{OH}$ and one molecule of KET, while the second decomposed KET to products and one molecule of $\mathrm{OH}$. The only noticeable opposition to the explosiveness of the mixture was provided by reaction group $\mathrm{R}^{3289 \mathrm{f}}$, which led to the formation of olefins $(\mathrm{Q})$ and $\mathrm{HO}_{2}$ through the decomposition of the alkylperoxy radicals $\left(\mathrm{RO}_{2}\right)$, therefore competing with the action of the path established by the most active reaction group $R^{3295 f}$. It was noted that the effect of $R^{3295 f}, R^{3399 f}, R^{3418 f}$ and $R^{3289 f}$ decreased with time. Figure 11 displays the general oxidation scheme of $n$-heptane [75, 80]. It is shown that two paths were created and they compete: the upper branch led eventually to the formation of one $\mathrm{OH}$ through reaction group $\mathrm{R}^{3289 \mathrm{f}}$ and the lower branch led to the formation of two $\mathrm{OH}$ molecules through reaction group $\mathrm{R}^{3295 f}$, therefore being more reactive than the upper branch. The competition between $\mathrm{R}^{3289 f}$ and $\mathrm{R}^{3295 f}$ resulted in the NTC behavior of $n$-heptane. Thus, the critical role of the isomerization reaction group $\mathrm{R}^{3295 \mathrm{f}}$ is highlighted, being the reaction group that directly competed with $\mathrm{R}^{3289 \mathrm{f}}$, and therefore the group that determined the reactivity of the mixture. Consequently, the large TPI value of $\mathrm{R}^{3295 \mathrm{f}}$ was justifiable.

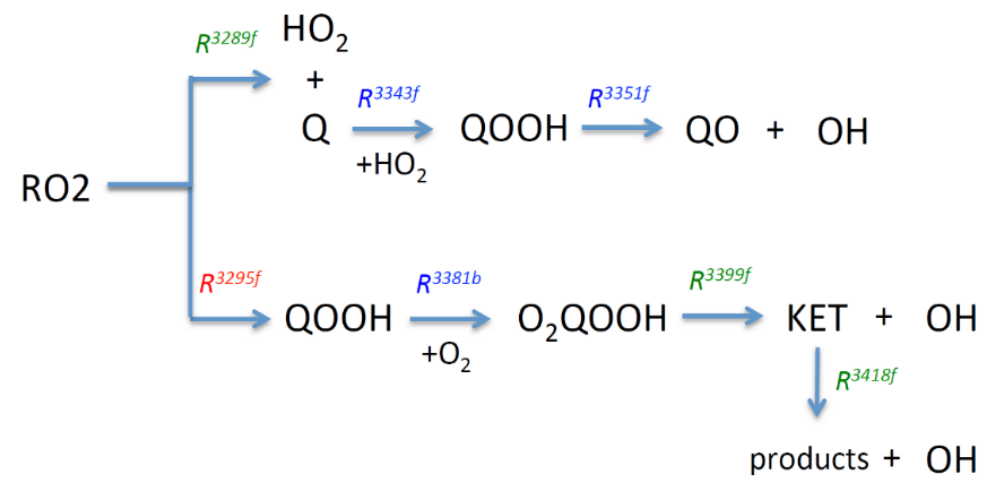


Figure 11: General oxidation path of $n$-heptane/air, when $\mathrm{T}_{0}=750 \mathrm{~K}, \mathrm{P}_{0}=40$ bar; $\mathrm{R}: \mathrm{C}_{7} \mathrm{H}_{15}, \mathrm{Q}$ : $\mathrm{C}_{7} \mathrm{H}_{14}$. Red/green represents reactions with large/medium TPI values; blue represents reactions with negligible TPI values.

Table 2 shows that in the case of the $60 \% n$-heptane and $40 \%$ iso-octane blend, during the first ignition stage, $\tau_{e, f}$ was mainly generated by reaction groups $\mathrm{R}^{3295 \mathrm{f}}, \mathrm{R}^{3399 \mathrm{f}}, \mathrm{R}^{3418 \mathrm{f}}$ and $\mathrm{R}^{3289 \mathrm{f}}$; the first three favoring, and the last one opposing its explosive character. As in the pure $n$-heptane case, their effect decreased with time. However, an additional contribution (favoring the explosive character of $\tau_{e, f}$ ) was provided by the $\mathrm{H}$-abstraction reaction group $\mathrm{R}^{3054 \mathrm{f}}$, which led to the formation of $n$-heptane alkyl radicals. Finally, a considerable opposition to the explosive character of $\tau_{e, f}$ was provided by the $\mathrm{H}$-abstraction reaction group $\mathrm{R}^{6772 \mathrm{f}}$, which competed with the action of $\mathrm{R}^{3054 \mathrm{f}}$ and consumed iso-octane, leading to the formation of $i s o$-octane alkyl radicals. The larger value of $\tau_{e, f}$ in this case--in comparison to the $n$-heptane--can be attributed to the smaller (both relative and absolute) contributions of reaction groups $R^{3295 f}, R^{3399 f}, R^{3418 f}$ and $R^{3289 f}$ and to the emergence of reaction group $\mathrm{R}^{6772 \mathrm{f}}$ which competed with the action of $\mathrm{R}^{3054 \mathrm{f}}$.

In the case of $60 \% n$-heptane and $40 \%$ ethanol, Table 2 shows that the contribution of the $\mathrm{H}$ abstraction reaction group $\mathrm{R}^{3054 \mathrm{f}}$ increased considerably when compared to the $60 \% n$-heptane and $40 \%$ iso-octane, and became the dominant contributor. However, the H-abstraction reactions $366 / 367 \mathrm{f}$ also became significant contributors to the generation of $\tau_{e, f}$, competing with the action of $\mathrm{R}^{3054 \mathrm{f}}$ by consuming $\mathrm{C}_{2} \mathrm{H}_{5} \mathrm{OH}$ with $\mathrm{OH}$ and leading to the formation of $\mathrm{sC}_{2} \mathrm{H}_{4} \mathrm{OH} / \mathrm{pC}_{2} \mathrm{H}_{4} \mathrm{OH}$ radicals. However, the $\mathrm{H}$-abstraction path that relates to the consumption of $\mathrm{C}_{2} \mathrm{H}_{5} \mathrm{OH}$ and $\mathrm{OH}$ (i.e., reactions 366/367f) was less reactive than the $\mathrm{H}$-abstraction path that relates to the consumption of $n$-heptane (i.e., reaction group $\mathrm{R}^{3054 \mathrm{f}}$ ), therefore it opposed the explosiveness of the mixture. As a result, reaction group $\mathrm{R}^{3054 \mathrm{f}}$ had a much more pronounced role and competed with the action of reactions 366/367f. The increased role of the competition between $R^{3054 f}$ and 366/367f was one of the major differences compared to the $60 \% n$-heptane and $40 \%$ iso-octane blend where, as was shown, the competition between the $\mathrm{H}$-abstraction reaction groups $\mathrm{R}^{6772 \mathrm{f}}$ and $\mathrm{R}^{3054 \mathrm{f}}$ was found to be less significant in terms of the contributions of these reaction groups to $\tau_{e, f}$. This provided a physical understanding about the larger value of $\tau_{e, f}$ and the longer first-stage ignition of the $60 \%$ $n$-heptane and $40 \%$ ethanol blend compared to the $60 \%$-heptane and $40 \%$ iso-octane blend. Moreover, the relative contributions of reaction groups $\mathrm{R}^{3295 \mathrm{f}}, \mathrm{R}^{3399 \mathrm{f}}$ and $\mathrm{R}^{3418 \mathrm{f}}$ (all favoring the explosive character of $\tau_{e, f}$ and, therefore, promoting ignition), decreased significantly (7-10\% for each) compared to the $60 \% n$-heptane and $40 \%$ iso-octane case. Additionally, the contribution of the reaction group $\mathrm{R}^{3289 \mathrm{f}}$, which opposed the generation of the explosive timescale (thus, opposing the explosiveness of the mixture), decreased very little (1-1.5\%).

In summary, during the first ignition stage, the results displayed in Table 2 indicate that the addition of $i$ so-octane or ethanol to the initial mixture of $n$-heptane/air resulted in the activation of the $\mathrm{H}$-abstraction reaction group $\mathrm{F}+\mathrm{OH} \rightarrow \mathrm{R}+\mathrm{H}_{2} \mathrm{O}$, where $\mathrm{F}$ was $i$ so-octane or ethanol (reactions $\mathrm{R}^{6772 \mathrm{f}}$ and $366 / 367 \mathrm{f}$ respectively). In general, H-abstraction reactions favored the explosiveness of a mixture. However, since pure iso-octane and ethanol are less reactive than pure $n$-heptane, the $\mathrm{H}$-abstraction reactions that related to the consumption of iso-octane and ethanol competed with the $\mathrm{H}$-abstraction reactions of $n$-heptane, which obtained a more pronounced role. So, essentially the role of the $\mathrm{H}$-abstraction reactions of $n$-heptane was to counterbalance the action of the $\mathrm{H}$ abstraction reactions of $i$ so-octane or ethanol. Therefore, the contribution of $\mathrm{R}^{3054 \mathrm{f}}$ increased to the same magnitude of $\mathrm{R}^{6772 \mathrm{f}}$ and $366 / 367 \mathrm{f}$. However, it is noted that the contribution of the $\mathrm{H}$ - 
abstraction reactions that related to the consumption of ethanol (i.e., reactions 366/367f) was much greater than the contribution related to the consumption of iso-octane (although ethanol is less reactive than iso-octane). This can be explained by the fact that reactions $366 / 367 \mathrm{f}$ had lower activation energies than reactions $\mathrm{R}^{6772 \mathrm{f}}$.

Table 2: Values of the largest TPI $\left(J_{k}^{e}\right)$ during first ignition stage of constant volume autoignition of fuel blends; $n$-heptane (up), $60 \% n$-heptane and 40\% iso-octane (middle) and 60\% $n$-heptane and $40 \%$ ethanol (bottom). Only values larger than $2 \%$ are displayed. $\mathrm{To}=750 \mathrm{~K}, \mathrm{Po}=40 \mathrm{bar}$.

\begin{tabular}{|c|c|c|c|c|c|c|c|}
\hline & & \multicolumn{2}{|c|}{$\mathrm{P}_{1}$} & \multicolumn{2}{|c|}{$\mathrm{P}_{2}$} & \multicolumn{2}{|c|}{$\mathrm{P}_{3}$} \\
\hline \multirow{8}{*}{ 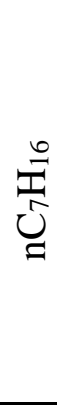 } & $t[s]$ & \multicolumn{2}{|c|}{$0.00 \mathrm{E}+00$} & \multicolumn{2}{|c|}{$6.15 \mathrm{E}-04$} & \multicolumn{2}{|c|}{$1.21 \mathrm{E}-03$} \\
\hline & $\tau_{e, f}[s]$ & \multicolumn{2}{|c|}{ 7.89E-05 } & \multicolumn{2}{|c|}{ 7.91E-05 } & \multicolumn{2}{|c|}{$9.31 \mathrm{E}-05$} \\
\hline & $T[K]$ & \multicolumn{2}{|c|}{750.00} & \multicolumn{2}{|c|}{750.00} & \multicolumn{2}{|r|}{764.71} \\
\hline & & $\mathrm{R}^{3295 \mathrm{f}}$ & $31.85 \%$ & $\mathrm{R}^{3295 \mathrm{f}}$ & $31.85 \%$ & $\mathrm{R}^{3295 \mathrm{f}}$ & $19.37 \%$ \\
\hline & & $\mathrm{R}^{3399 \mathrm{f}}$ & $22.28 \%$ & $\mathrm{R}^{3399 \mathrm{f}}$ & $22.41 \%$ & $\mathrm{R}^{3399 \mathrm{f}}$ & $11.72 \%$ \\
\hline & & $\mathrm{R}^{3289 \mathrm{f}}$ & $-11.49 \%$ & $\mathrm{R}^{3289 \mathrm{f}}$ & $-11.50 \%$ & $\mathrm{R}^{3289 \mathrm{f}}$ & $-9.49 \%$ \\
\hline & & $\mathrm{R}^{3418 \mathrm{f}}$ & $10.86 \%$ & $\mathrm{R}^{3418 \mathrm{f}}$ & $10.87 \%$ & $\mathrm{R}^{3054 \mathrm{f}}$ & $6.08 \%$ \\
\hline & & & & & & $\mathrm{R}^{3418 \mathrm{f}}$ & $3.17 \%$ \\
\hline \multirow{9}{*}{ 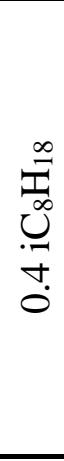 } & $t[s]$ & \multirow{3}{*}{\multicolumn{2}{|c|}{$\begin{array}{c}0.00 \mathrm{E}+00 \\
9.51 \mathrm{E}-05 \\
750.00\end{array}$}} & \multicolumn{2}{|c|}{ 7.13E-04 } & \multicolumn{2}{|c|}{$1.40 \mathrm{E}-03$} \\
\hline & $\tau_{e, f}[s]$ & & & 9.5 & -05 & 1.1 & E-04 \\
\hline & $T[K]$ & & & \multicolumn{2}{|c|}{750.00} & \multicolumn{2}{|c|}{757.93} \\
\hline & & $\mathrm{R}^{3295 \mathrm{f}}$ & $24.10 \%$ & $\mathrm{R}^{3295 \mathrm{f}}$ & $24.10 \%$ & $\mathrm{R}^{3295 \mathrm{f}}$ & $15.94 \%$ \\
\hline & & $\mathrm{R}^{3399 \mathrm{f}}$ & $16.63 \%$ & $\mathrm{R}^{3399 \mathrm{f}}$ & $16.63 \%$ & $\mathrm{R}^{3399 \mathrm{f}}$ & $9.91 \%$ \\
\hline & & $\mathrm{R}^{3289 \mathrm{f}}$ & $-9.64 \%$ & $\mathrm{R}^{3289 \mathrm{f}}$ & $-9.64 \%$ & $\mathrm{R}^{3054 \mathrm{f}}$ & $8.79 \%$ \\
\hline & & $\mathrm{R}^{3418 \mathrm{f}}$ & $7.70 \%$ & $\mathrm{R}^{3418 \mathrm{f}}$ & $7.70 \%$ & $\mathrm{R}^{3289 \mathrm{f}}$ & $-8.12 \%$ \\
\hline & & $\mathrm{R}^{3054 \mathrm{f}}$ & $6.97 \%$ & $\mathrm{R}^{3054 \mathrm{f}}$ & $6.97 \%$ & $\mathrm{R}^{6772 \mathrm{f}}$ & $3.94 \%$ \\
\hline & & $\mathrm{R}^{6772 \mathrm{f}}$ & $-6.82 \%$ & $\mathrm{R}^{6772 \mathrm{f}}$ & $-6.82 \%$ & $\mathrm{R}^{3418 \mathrm{f}}$ & $2.98 \%$ \\
\hline \multirow{9}{*}{ 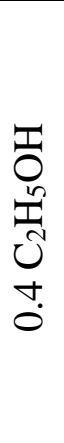 } & $t[s]$ & \multirow{3}{*}{\multicolumn{2}{|c|}{$\begin{array}{c}0.00 \mathrm{E}+00 \\
2.21 \mathrm{E}-05 \\
750.00\end{array}$}} & \multicolumn{2}{|c|}{$7.86 \mathrm{E}-04$} & \multicolumn{2}{|c|}{$1.51 \mathrm{E}-03$} \\
\hline & $\tau_{e, f}[s]$ & & & 2.21 & -04 & 2.7 & E-04 \\
\hline & $T[K]$ & & & \multicolumn{2}{|c|}{750.00} & \multicolumn{2}{|c|}{751.72} \\
\hline & & $\mathrm{R}^{3054 \mathrm{f}}$ & $22.07 \%$ & $\mathrm{R}^{3054 \mathrm{f}}$ & $22.08 \%$ & $R^{3054 f}$ & $22.72 \%$ \\
\hline & & $366 / 367 f$ & $-21.34 \%$ & $366 / 367 f$ & $-21.35 \%$ & $366 / 367 f$ & $-21.53 \%$ \\
\hline & & $\mathrm{R}^{3295 \mathrm{f}}$ & $13.60 \%$ & $\mathrm{R}^{3295 \mathrm{f}}$ & $13.57 \%$ & $\mathrm{R}^{3295 \mathrm{f}}$ & $10.73 \%$ \\
\hline & & $\mathrm{R}^{3399 \mathrm{f}}$ & $9.350 \%$ & $\mathrm{R}^{3399 \mathrm{f}}$ & $9.32 \%$ & $\mathrm{R}^{3289 \mathrm{f}}$ & $-7.94 \%$ \\
\hline & & $\mathrm{R}^{3289 \mathrm{f}}$ & $-8.35 \%$ & $\mathrm{R}^{3289 \mathrm{f}}$ & $-8.35 \%$ & $\mathrm{R}^{3399 \mathrm{f}}$ & $6.81 \%$ \\
\hline & & $\mathrm{R}^{3058 \mathrm{f}}$ & $4.29 \%$ & $\mathrm{R}^{3058 \mathrm{f}}$ & $4.23 \%$ & & \\
\hline
\end{tabular}
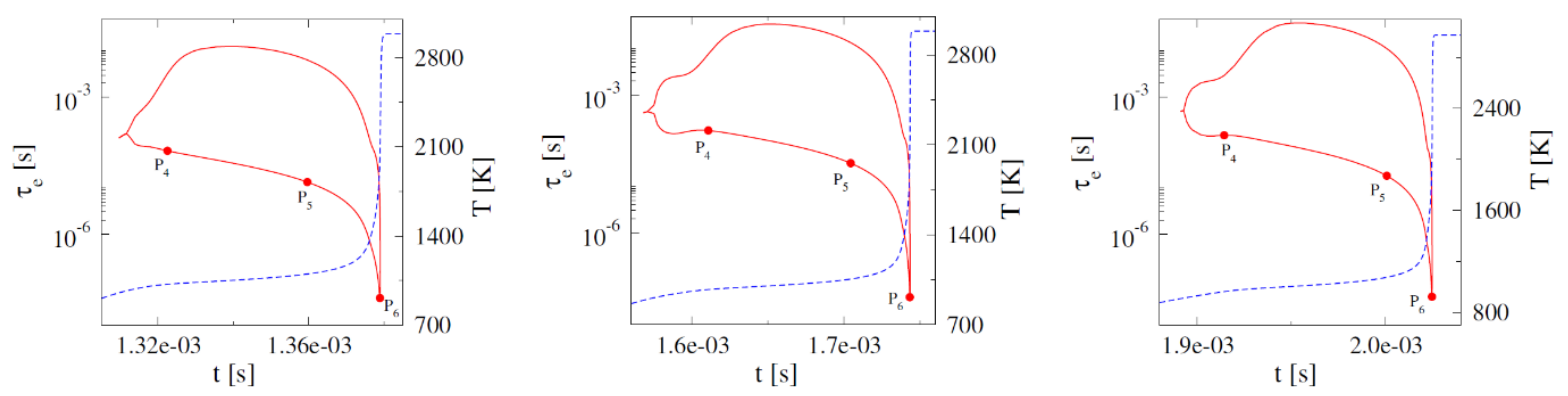

Figure 12: Developing explosive time scales and temperature evolution during second ignition stage of $n$-heptane/air (left), $60 \% n$ heptane and 40\% iso-octane (middle) and 60\% $n$-heptane and 40\% ethanol (right) mixtures. Points displayed represent selected points in Table $3 ; \mathrm{T}_{0}=750 \mathrm{~K}, \mathrm{P}_{0}=4 \mathrm{MPa}$. 
Figure 12 displays the evolution of temperature and $\tau_{e, f}$ during the second ignition stage, along with the three selected points in which CSP diagnostics were generated for all three mixtures, i.e., $n$-heptane/air, 60\% n-heptane and 40\% iso-octane and 60\% n-heptane and 40\% ethanol. Table 3 summarizes the TPI diagnostics to $\tau_{e, f}$ for the three selected points displayed in Fig. 12. In general, in all three cases considered here, the second stage was dominated by hydrogen related reactions. In particular (initially, at point $\left.\mathrm{P}_{4}\right) \tau_{e, f}$ was mainly generated by reactions $18 / 19 \mathrm{f}$ and $1 \mathrm{f}$. Reactions $18 / 19 \mathrm{f}$ led to the formation of two $\mathrm{OH}$ molecules and have been found to play a significant role in accelerating the ignition of $\mathrm{CH}_{4}, \mathrm{DME}, \mathrm{EtOH}$ and $n$-hexane [35, 46, 57]. Additionally, the importance of the chain branching reaction $1 \mathrm{f}$ is well known and has been widely documented. A minimal contribution to the generation of $\tau_{e, f}$ (opposing its explosive character), was provided by the chain termination reaction 16/17f, which consumed two $\mathrm{HO}_{2}$ molecules, forming $\mathrm{H}_{2} \mathrm{O}_{2}$ and $\mathrm{O}_{2}$. Similar behavior was observed in the case of $\mathrm{CH}_{4}$, DME, ethanol and $n$-hexane oxidation [35, 46, 57]. Moreover, the chain branching reaction 144f, which consumed $\mathrm{CH}_{3}$ radicals and produced $\mathrm{CH}_{3} \mathrm{O}$ and $\mathrm{OH}$, was also found to provide a fair contribution to $\tau_{e, f}$ in the oxidation of DME and ethanol in the last of the explosive stage. Finally, the chain carrying reaction $302 \mathrm{f}$ offered some positive, if insignificant contribution, favoring the explosiveness of the mixture at that stage. In fact, this was the first difference between the pure $n$-heptane and the other two cases, where the effect of this particular reaction was replaced by the negative contribution of reaction 671f, which formed $\mathrm{RO}_{2}$ through the reaction of $n$-heptane with $\mathrm{O}_{2}$. The second noticeable difference at that point was that the effect of reaction $18 / 19 \mathrm{f}$ in the $60 \% n$-heptane and $40 \%$ ethanol case significantly decreased, compared to the pure $n$-heptane case, thus providing an explanation for the increased value of the explosive timescale.

Table 3: Values of largest TPI $\left(J_{k}^{e}\right)$ during second ignition stage of constant volume autoignition of fuel blends; $n$-heptane (up), $60 \% n$-heptane and 40\% iso-octane (middle) and 60\% $n$-heptane and $40 \%$ ethanol (bottom). Only values larger than $2 \%$ are displayed. $\mathrm{T}_{0}=750 \mathrm{~K}, \mathrm{P}_{0}=40$ bar.

\begin{tabular}{|c|c|c|c|c|c|c|c|}
\hline & & \multicolumn{2}{|c|}{$\mathrm{P}_{1}$} & \multicolumn{2}{|c|}{$\mathrm{P}_{2}$} & \multicolumn{2}{|c|}{$\mathrm{P}_{3}$} \\
\hline \multirow{10}{*}{$\underbrace{\stackrel{T}{T}}_{\mathscr{U}}$} & $t[s]$ & \multicolumn{2}{|c|}{ 1.32E-03 } & \multicolumn{2}{|c|}{$1.36 \mathrm{E}-03$} & \multicolumn{2}{|c|}{$1.38 \mathrm{E}-03$} \\
\hline & $\tau_{e, f}[s]$ & \multicolumn{2}{|c|}{$6.60 \mathrm{E}-05$} & \multicolumn{2}{|c|}{$1.37 \mathrm{E}-05$} & \multicolumn{2}{|c|}{ 3.94E-08 } \\
\hline & $T[K]$ & \multicolumn{2}{|c|}{1021.81} & \multicolumn{2}{|c|}{1101.62} & \multicolumn{2}{|c|}{2031.30} \\
\hline & & $18 / 19 \mathrm{f}$ & $11.10 \%$ & $18 / 19 f$ & $20.55 \%$ & $1 \mathrm{f}$ & $36.57 \%$ \\
\hline & & 1f & $10.90 \%$ & $1 \mathrm{f}$ & $8.26 \%$ & $3 f$ & $9.78 \%$ \\
\hline & & $16 / 17 f$ & $-2.77 \%$ & $16 / 17 f$ & $-5.40 \%$ & $8 \mathrm{f}$ & $-7.36 \%$ \\
\hline & & $144 f$ & $2.61 \%$ & $302 f$ & $5.21 \%$ & $3 b$ & $6.10 \%$ \\
\hline & & $302 \mathrm{f}$ & $2.56 \%$ & $12 \mathrm{f}$ & $4.17 \%$ & & \\
\hline & & & & $15 f$ & $-3.23 \%$ & & \\
\hline & & & & $144 \mathrm{f}$ & $3.18 \%$ & & \\
\hline \multirow{8}{*}{$\begin{array}{l}\stackrel{\infty}{\pi} \\
\bigcup_{0}^{\infty} \\
+ \\
+\end{array}$} & $t[s]$ & \multicolumn{2}{|c|}{$1.61 \mathrm{E}-03$} & \multicolumn{2}{|c|}{$1.70 \mathrm{E}-03$} & \multicolumn{2}{|c|}{$1.74 \mathrm{E}-03$} \\
\hline & $\tau_{e, f}[s]$ & \multicolumn{2}{|c|}{$1.66 \mathrm{E}-04$} & \multicolumn{2}{|c|}{$3.23 \mathrm{E}-05$} & \multicolumn{2}{|c|}{$3.96 \mathrm{E}-08$} \\
\hline & $T[K]$ & \multicolumn{2}{|c|}{973.98} & \multicolumn{2}{|c|}{1055.99} & \multicolumn{2}{|c|}{2062.87} \\
\hline & & $18 / 19 f$ & $10.01 \%$ & $18 / 19 f$ & $21.15 \%$ & $1 \mathrm{f}$ & $35.97 \%$ \\
\hline & & 1f & $9.03 \%$ & 1f & $7.18 \%$ & $3 \mathrm{f}$ & $10.53 \%$ \\
\hline & & $16 / 17 f$ & $-2.80 \%$ & $16 / 17 f$ & $-5.28 \%$ & $8 f$ & $-8.43 \%$ \\
\hline & & $144 f$ & $2.43 \%$ & $12 \mathrm{f}$ & $3.52 \%$ & $3 b$ & $-6.98 \%$ \\
\hline & & $671 \mathrm{f}$ & $-2.31 \%$ & $144 f$ & $3.35 \%$ & & \\
\hline
\end{tabular}




\begin{tabular}{|c|c|c|c|c|c|c|c|}
\hline & & & & $\begin{array}{l}15 \mathrm{f} \\
302 \mathrm{f}\end{array}$ & $\begin{array}{l}-2.93 \% \\
2.88 \%\end{array}$ & & \\
\hline & $t[s]$ & & $\overline{\mathrm{E}-03}$ & & $\overline{E-03}$ & & E-03 \\
\hline & $\tau_{e, f}[s]$ & & E-04 & & E-05 & & E-08 \\
\hline & $T[K]$ & & .53 & & 5.75 & & 2.84 \\
\hline$i_{i=0}$ & & 1f & $9.13 \%$ & 18/19f & $24.36 \%$ & $1 \mathrm{ff}$ & $36.48 \%$ \\
\hline 工 & & $18 / 19 \mathrm{f}$ & $6.19 \%$ & 1f & $6.62 \%$ & $3 \mathrm{f}$ & $9.50 \%$ \\
\hline t. & & $671 \mathrm{f}$ & $-2.98 \%$ & $16 / 17 \mathrm{f}$ & $-5.82 \%$ & $8 \mathrm{f}$ & $-7.24 \%$ \\
\hline & & $144 \mathrm{f}$ & $2.47 \%$ & $302 \mathrm{f}$ & $4.01 \%$ & $3 b$ & $-6.06 \%$ \\
\hline & & $16 / 17 \mathrm{f}$ & $-2.34 \%$ & $12 \mathrm{f}$ & $3.97 \%$ & & \\
\hline & & & & $144 \mathrm{f}$ & $3.68 \%$ & & \\
\hline & & & & $15 f$ & $-3.05 \%$ & & \\
\hline
\end{tabular}

Figure 12 shows that, as the process progressed during the second stage, $\tau_{e, f}$ accelerated. As shown by the results displayed in Table 3 for point $\mathrm{P}_{5}$, its acceleration resulted mainly from the increased influence of reactions 18/19f. The influence of reactions $1 \mathrm{f}$ and 144f, 15/16f slightly dropped, and increased, respectively. Fair contributions at this point were also provided by reactions $12 \mathrm{f}, 302 \mathrm{f}$ and $15 \mathrm{f}$; the first two favoring the explosiveness of the mixture while the latter opposed the explosive character of $\tau_{e, f}$. To summarize: Reaction $12 \mathrm{f}$ is a chain branching reaction that led to the formation of two $\mathrm{OH}$ molecules, like reaction 18/19f, which was the main contributor to $\tau_{e, f}$ at this point. Reaction $302 \mathrm{f}$ was an $\mathrm{H}$-abstraction chain propagating reaction that consumed ethylene $\left(\mathrm{C}_{2} \mathrm{H}_{4}\right)$ (also a fuel) and created the unstable $\mathrm{C}_{2} \mathrm{H}_{3}$. The role of this reaction was previously highlighted during the second ignition stage of $n$-hexane [37]. Finally, reaction $15 \mathrm{f}$ is a chain termination reaction that led to the formation of two stable molecules, so it opposed ignition.

At the end of the explosive stage, where the acceleration of $\tau_{e, f}$ intensified, the dominant contributor to the generation of $\tau_{e, f}$ became the chain branching reaction 1f. As shown in the results for point $\mathrm{P}_{6}$ of Table 3, the effect of reactions 18/19f diminished, but additional positive contribution was provided by the highly exothermic reaction $3 \mathrm{f}$, which correlated to the high temperature reached at this point. The major opposition to the explosiveness of the mixture was provided by the chain termination reaction $8 \mathrm{f}$ and reaction $3 \mathrm{~b}$ which competed with the action of 3 f.

In summary: The second stage in all three cases considered here was dominated mainly by hydrogen related reactions, regardless of the initial mixture. Initially, reaction 18/19f--and later 1f-were the dominant reactions favoring the explosiveness of the mixture. The major opposition to the explosiveness of the mixture was provided by reactions $16 / 17 \mathrm{f}$ (initially) and (later) $8 \mathrm{f}, 3 \mathrm{~b}$. The only significant carbon related reactions were $144 \mathrm{f}$ and $302 \mathrm{f}$, both favoring the explosive character of $\tau_{e, f}$, and they increased slightly over time.

\section{Conclusions}

This study presented chemical insights into the effect of ethanol addition on the ignition of $n$ heptane by interrogating the low temperature chemistry suppression of ethanol as a radical scavenger. Its efficacy as an ignition inhibitor was compared with iso-octane, which showed very low LTC behavior, but less radical scavenging ability. Ethanol was found to suppress the reactivity in mixtures, as shown by reduced $\mathrm{OH}$ mole fraction when compared to iso-octane. $\mathrm{HO}_{2}$ radical, 
however, was higher in ethanol-containing blends, due to the formation of alphahydroxyethyl radicals, which reacted with $\mathrm{O}_{2}$ to form $\mathrm{HO}_{2}$ radicals.

Further, a computational singular perturbation method was used to investigate the reactions responsible for ignition. It was found that the first ignition stage (which determines the overall ignition delay time of the mixture) was dominated by carbon related reactions, as opposed to the second stage, which was dominated by hydrogen related reactions. In particular, the first ignition stage was mainly determined by the isomerization of alkyl peroxy radicals $\left(\mathrm{RO}_{2}\right)$ to hydroperoxyalkyl radicals $(\mathrm{QOOH})$. An additional contribution was provided by the decomposition of $\mathrm{O} 2 \mathrm{QOOH}$ to $\mathrm{KET}$ and $\mathrm{OH}$, and the decomposition of KET to products and $\mathrm{OH}$. When iso-octane or ethanol was added to the initial mixture, the $\mathrm{H}$-abstraction path of $n$-heptane through $\mathrm{OH}$ was enhanced and competed with that of iso-octane/ethanol. It was found that the $\mathrm{H}$-abstraction path of ethanol was more favored than the path of the iso-octane, as a result of the smaller activation energies of the related reactions. The competition of the $\mathrm{H}$-abstraction paths resulted in a smaller radical pool in the $n$-heptane-iso-octane-air case, and an even smaller radical in the $n$-heptaneethanol-air. Finally, the second ignition stage was controlled by the same set of reactions in all three cases, both qualitatively and quantitatively. Overall, with the knowledge of specific reactions responsible for auto-ignition of ethanol blends, better optimized blends can be achieved.

The computationally expensive nature of the CSP approach used in the current study limited the analysis to $n$-heptane blends. Expanding the analysis to other primary reference fuels--and ultimately to complex surrogates--is the natural next step. Such an analysis could provide further insight into reactions responsible for auto-ignition of alcohol blends in complex gasoline fuel. Furthermore, using CSP analysis allowed the study of the dynamics of the reactions responsible for auto-ignition for ethanol- $n$-heptane mixture, and key reactions were noted.

\section{Acknowledgments:}

The research reported in this publication was supported by competitive research funding from King Abdullah University of Science and Technology (KAUST), awarded to the Clean Combustion Research Center (CCRC).

\section{References:}

[1] J. G. Olivier, J. A. Peters, and G. Janssens-Maenhout, "Trends in global CO2 emissions 2012 report," 2012.

[2] E. Singh, M. Waqas, B. Johansson, and M. Sarathy, "Simulating HCCI Blending Octane Number of Primary Reference Fuel with Ethanol," SAE Technical Paper0148-7191, 2017.

[3] E. Singh, P. Hlaing, H. Shi, and R. Dibble, "Effect of Different Fluids on Injection Strategies to Suppress Pre-Ignition," SAE Technical Paper0148-7191, 2019.

[4] E. Singh, J. Badra, M. Mehl, and S. M. Sarathy, "Chemical Kinetic Insights into the Octane Number and Octane Sensitivity of Gasoline Surrogate Mixtures," Energy \& Fuels, vol. 31, no. 2, pp. 1945-1960, 2017.

[5] A. D. Puckett, "Knock ratings of gasoline substitutes," J. Res. Natl. Bur. Stand, vol. 35, no. 4, pp. 273-284, 1945.

[6] J. C. Porter and R. Wiebe, "Alcohol as an antiknock agent in automotive engines," Industrial \& Engineering Chemistry, vol. 44, no. 5, pp. 1098-1104, 1952. 
[7] J. E. Anderson et al., "Octane numbers of ethanol-gasoline blends: measurements and novel estimation method from molar composition," SAE Technical Paper0148-7191, 2012.

[8] M. K. Shukla, E. Singh, N. Singh, and S. Singal, "Prospects of 2, 5-dimethylfuran as a fuel: physico-chemical and engine performance characteristics evaluation," Journal of Material Cycles and Waste Management, vol. 17, no. 3, pp. 459-464, 2015.

[9] E. Singh, V. S. B. Shankar, R. Tripathi, H. Pitsch, and S. M. Sarathy, "2-Methylfuran: A bioderived octane booster for spark-ignition engines," Fuel, vol. 225, pp. 349-357, 2018.

[10] E. Monroe et al., "Discovery of novel octane hyperboosting phenomenon in prenol biofuel/gasoline blends," Fuel, vol. 239, pp. 1143-1148, 2019.

[11] T. M. Foong, K. J. Morganti, M. J. Brear, G. da Silva, Y. Yang, and F. L. Dryer, "The octane numbers of ethanol blended with gasoline and its surrogates," Fuel, vol. 115, pp. 727-739, 2014.

[12] R. L. McCormick, "Co-Optimization of Internal Combustion Engines and Biofuels," National Renewable Energy Lab.(NREL), Golden, CO (United States)2016.

[13] V. Knop, M. Loos, C. Pera, and N. Jeuland, "A linear-by-mole blending rule for octane numbers of n-heptane/iso-octane/toluene mixtures," Fuel, vol. 115, pp. 666-673, 2014.

[14] N. Rankovic, G. Bourhis, M. Loos, and R. Dauphin, "Understanding octane number evolution for enabling alternative low RON refinery streams and octane boosters as transportation fuels," Fuel, vol. 150, pp. 41-47, 2015.

[15] G. Kalghatgi, R. Head, J. Chang, Y. Viollet, H. Babiker, and A. Amer, "An alternative method based on toluene/n-heptane surrogate fuels for rating the anti-knock quality of practical gasolines," SAE International Journal of Fuels and Lubricants, vol. 7, no. 2014-01-2609, pp. 663-672, 2014.

[16] G. Kalghatgi, H. Babiker, and J. Badra, "A simple method to predict knock using toluene, nheptane and iso-octane blends (TPRF) as gasoline surrogates," SAE International Journal of Engines, vol. 8, no. 2015-01-0757, pp. 505-519, 2015.

[17] J. Badra, A. S. AlRamadan, and S. M. Sarathy, "Optimization of the octane response of gasoline/ethanol blends," Applied Energy, vol. 203, pp. 778-793, 2017.

[18] C. Wang, S. Zeraati-Rezaei, L. Xiang, and H. Xu, "Ethanol blends in spark ignition engines: RON, octane-added value, cooling effect, compression ratio, and potential engine efficiency gain," Applied energy, vol. 191, pp. 603-619, 2017.

[19] M. Waqas, N. Naser, M. Sarathy, K. Morganti, K. Al-Qurashi, and B. Johansson, "Blending Octane Number of Ethanol in HCCI, SI and CI Combustion Modes," SAE International Journal of Fuels and Lubricants, vol. 9, no. 2016-01-2298, pp. 659-682, 2016.

[20] S. M. Sarathy, P. Oßwald, N. Hansen, and K. Kohse-Höinghaus, "Alcohol combustion chemistry," Progress in energy and Combustion Science, vol. 44, pp. 40-102, 2014.

[21] D. Bradley and R. Head, "Engine autoignition: The relationship between octane numbers and autoignition delay times," Combustion and Flame, vol. 147, no. 3, pp. 171-184, 2006.

[22] P. L. Perez and A. L. Boehman, "Experimental investigation of the autoignition behavior of surrogate gasoline fuels in a constant-volume combustion bomb apparatus and its relevance to HCCI combustion," Energy \& fuels, vol. 26, no. 10, pp. 6106-6117, 2012.

[23] K. Fieweger, R. Blumenthal, and G. Adomeit, "Shock-tube investigations on the self-ignition of hydrocarbon-air mixtures at high pressures," in Symposium (International) on Combustion, 1994, vol. 25, no. 1, pp. 1579-1585: Elsevier. 
[24] K. Fieweger, R. Blumenthal, and G. Adomeit, "Self-ignition of SI engine model fuels: a shock tube investigation at high pressure," Combustion and Flame, vol. 109, no. 4, pp. 599-619, 1997.

[25] M. Mehl, J.-Y. Chen, W. J. Pitz, S. M. Sarathy, and C. K. Westbrook, "An approach for formulating surrogates for gasoline with application toward a reduced surrogate mechanism for CFD engine modeling," Energy \& Fuels, vol. 25, no. 11, pp. 5215-5223, 2011.

[26] S. M. Sarathy et al., "A comprehensive combustion chemistry study of 2, 5-dimethylhexane," Combustion and Flame, vol. 161, no. 6, pp. 1444-1459, 2014.

[27] J. A. Badra et al., "A methodology to relate octane numbers of binary and ternary n-heptane, iso-octane and toluene mixtures with simulated ignition delay times," Fuel, vol. 160, pp. 458469, 2015.

[28] C. K. Westbrook, M. Mehl, W. J. Pitz, and M. Sjöberg, "Chemical kinetics of octane sensitivity in a spark-ignition engine," Combustion and Flame, vol. 175, pp. 2-15, 2017.

[29] C. Westbrook, M. Sjöberg, and N. Cernansky, "A new chemical kinetic method of determining Ron and Mon values for single component and multicomponent mixtures of engine fuels," Combustion and Flame, 2018.

[30] N. Naser, S. M. Sarathy, and S. H. Chung, "Estimating fuel octane numbers from homogeneous gas-phase ignition delay times," Combustion and Flame, vol. 188, pp. 307-323, 2018.

[31] S. Lam and D. Goussis, "Understanding complex chemical kinetics with computational singular perturbation," in Symposium (International) on Combustion, 1989, vol. 22, no. 1, pp. 931-941: Elsevier.

[32] S. Lam and D. Goussis, "The CSP method for simplifying kinetics," International Journal of Chemical Kinetics, vol. 26, no. 4, pp. 461-486, 1994.

[33] D. J. Diamantis, E. Mastorakos, and D. A. Goussis, "H2/air autoignition: The nature and interaction of the developing explosive modes," Combustion Theory and Modelling, vol. 19, no. 3, pp. 382-433, 2015.

[34] E. A. Tingas, H. G. Im, D. C. Kyritsis, and D. A. Goussis, "The use of CO2 as an additive for ignition delay and pollutant control in CH4/air autoignition," Fuel, vol. 211, pp. 898-905, 2018.

[35] E.-A. Tingas, D. C. Kyritsis, and D. A. Goussis, "Comparative investigation of homogeneous autoignition of DME/air and EtOH/air mixtures at low initial temperatures," Combustion Theory and Modelling, vol. 21, no. 1, pp. 93-119, 2017.

[36] E. A. Tingas, D. C. Kyritsis, and D. A. Goussis, "Ignition delay control of DME/air and EtOH/air homogeneous autoignition with the use of various additives," Fuel, vol. 169, pp. 1524, 2016.

[37] E.-A. Tingas, Z. Wang, S. M. Sarathy, H. G. Im, and D. A. Goussis, "Chemical kinetic insights into the ignition dynamics of n-hexane," Combustion and Flame, vol. 188, pp. 28-40, 2018.

[38] J. Prager, H. N. Najm, M. Valorani, and D. Goussis, "Structure of n-heptane/air triple flames in partially-premixed mixing layers," Combustion and Flame, vol. 158, no. 11, pp. 2128-2144, 2011.

[39] M. Jaasim, E.-A. Tingas, F. E. H. Pérez, and H. G. Im, "Computational singular perturbation analysis of super-knock in SI engines," Fuel, vol. 225, pp. 184-191, 2018.

[40] A. Kazakov, M. Chaos, Z. Zhao, and F. L. Dryer, "Computational singular perturbation analysis of two-stage ignition of large hydrocarbons," The Journal of Physical Chemistry A, vol. 110, no. 21, pp. 7003-7009, 2006. 
[41] E. A. Tingas, D. C. Kyritsis, and D. A. Goussis, "Algorithmic determination of the mechanism through which $\mathrm{H} 2 \mathrm{O}$-dilution affects autoignition dynamics and $\mathrm{NO}$ formation in $\mathrm{CH}$ 4/air mixtures," Fuel, vol. 183, pp. 90-98, 2016.

[42] D. Goussis and G. Skevis, "Nitrogen chemistry controlling steps in methane-air premixed flames," Computational fluid and solid mechanics, vol. 1, pp. 650-653, 2005.

[43] D. Manias et al., "Analysis of Hydrogen/Air Turbulent Premixed Flames at Different Karlovitz Numbers Using Computational Singular Perturbation," in 2018 AIAA Aerospace Sciences Meeting, 2018, p. 0364.

[44] H. N. Najm, M. Valorani, D. A. Goussis, and J. Prager, "Analysis of methane-air edge flame structure," Combustion Theory and Modelling, vol. 14, no. 2, pp. 257-294, 2010.

[45] M. Kooshkbaghi, C. E. Frouzakis, K. Boulouchos, and I. V. Karlin, "n-Heptane/air combustion in perfectly stirred reactors: Dynamics, bifurcations and dominant reactions at critical conditions," Combustion and Flame, vol. 162, no. 9, pp. 3166-3179, 2015.

[46] D. M. Manias, E. A. Tingas, C. E. Frouzakis, K. Boulouchos, and D. A. Goussis, "The mechanism by which $\mathrm{CH} 2 \mathrm{O}$ and $\mathrm{H} 2 \mathrm{O} 2$ additives affect the autoignition of $\mathrm{CH}$ 4/air mixtures," Combustion and Flame, vol. 164, pp. 111-125, 2016.

[47] D. J. Diamantis, D. C. Kyritsis, and D. A. Goussis, "The reactions supporting or opposing the development of explosive modes: Auto-ignition of a homogeneous methane/air mixture," Proceedings of the Combustion Institute, vol. 35, no. 1, pp. 267-274, 2015.

[48] S. M. Sarathy et al., "Compositional effects on the ignition of FACE gasolines," Combustion and Flame, vol. 169, pp. 171-193, 2016.

[49] M. Sjoberg and J. E. Dec, "Ethanol autoignition characteristics and HCCI performance for wide ranges of engine speed, load and boost," SAE International Journal of Engines, vol. 3, no. 1, pp. 84-106, 2010.

[50] M. Sjöberg and J. E. Dec, "Effects of EGR and its constituents on HCCI autoignition of ethanol," Proceedings of the Combustion Institute, vol. 33, no. 2, pp. 3031-3038, 2011.

[51] D. Vuilleumier et al., "Intermediate temperature heat release in an HCCI engine fueled by ethanol/n-heptane mixtures: An experimental and modeling study," Combustion and flame, vol. 161, no. 3, pp. 680-695, 2014.

[52] D. M. Vuilleumier, "The Effect of Ethanol Addition to Gasoline on Low-and IntermediateTemperature Heat Release under Boosted Conditions in Kinetically Controlled Engines," UC Berkeley, 2016.

[53] J. P. Szybist and D. A. Splitter, "Pressure and temperature effects on fuels with varying octane sensitivity at high load in SI engines," Combustion and Flame, vol. 177, pp. 49-66, 2017.

[54] R. J. Kee, F. M. Rupley, and J. A. Miller, "Chemkin-II: A Fortran chemical kinetics package for the analysis of gas-phase chemical kinetics," Sandia National Labs., Livermore, CA (USA)1989.

[55] M. Mehl et al., "Detailed chemistry promotes understanding of octane numbers and gasoline sensitivity," Energy \& fuels, vol. 20, no. 6, pp. 2391-2398, 2006.

[56] M. Mehl, W. J. Pitz, C. K. Westbrook, and H. J. Curran, "Kinetic modeling of gasoline surrogate components and mixtures under engine conditions," Proceedings of the Combustion Institute, vol. 33, no. 1, pp. 193-200, 2011.

[57] E. A. Tingas, D. C. Kyritsis, and D. A. Goussis, "Autoignition dynamics of DME/air and EtOH/air homogeneous mixtures," Combustion and Flame, vol. 162, no. 9, pp. 3263-3276, 2015. 
[58] N. Naser, S. Y. Yang, G. Kalghatgi, and S. H. Chung, "Relating the octane numbers of fuels to ignition delay times measured in an ignition quality tester (IQT)," Fuel, vol. 187, pp. 117$127,2017$.

[59] Y. Huang, G. Hong, and R. Huang, "Investigation to charge cooling effect and combustion characteristics of ethanol direct injection in a gasoline port injection engine," Applied energy, vol. 160, pp. 244-254, 2015.

[60] T. M. Foong, K. J. Morganti, M. J. Brear, G. da Silva, Y. Yang, and F. L. Dryer, "The effect of charge cooling on the RON of ethanol/gasoline blends," SAE International Journal of Fuels and Lubricants, vol. 6, no. 2013-01-0886, pp. 34-43, 2013.

[61] S. G. Davis and C. K. Law, "Determination of and Fuel Structure Effects on Laminar Flame Speeds of C1 to C8 Hydrocarbons," Combustion Science and Technology, vol. 140, no. 1-6, pp. 427-449, 1998/12/01 1998.

[62] T. Hara and K. Tanoue, "Laminar flame speed of ethanol, n-heptane, iso-octane air mixtures," JSAE paper, vol. 20068518, 2006.

[63] T. M. Foong, M. J. Brear, K. J. Morganti, G. da Silva, Y. Yang, and F. L. Dryer, "Modeling end-gas autoignition of ethanol/gasoline surrogate blends in the cooperative fuel research engine," Energy \& Fuels, vol. 31, no. 3, pp. 2378-2389, 2017.

[64] J. Anderson et al., "High octane number ethanol-gasoline blends: Quantifying the potential benefits in the United States," Fuel, vol. 97, pp. 585-594, 2012.

[65] S. R. Daly, K. E. Niemeyer, W. J. Cannella, and C. L. Hagen, "Predicting fuel research octane number using Fourier-transform infrared absorption spectra of neat hydrocarbons," Fuel, vol. 183, pp. 359-365, 2016.

[66] M. Mehl, G. Vanhove, W. J. Pitz, and E. Ranzi, "Oxidation and combustion of the n-hexene isomers: A wide range kinetic modeling study," Combustion and Flame, vol. 155, no. 4, pp. 756-772, 2008.

[67] P. Zhang et al., "First-stage ignition delay in the negative temperature coefficient behavior: Experiment and simulation," Combustion and Flame, vol. 167, pp. 14-23, 2016.

[68] J. Zádor, C. A. Taatjes, and R. X. Fernandes, "Kinetics of elementary reactions in lowtemperature autoignition chemistry," Progress in Energy and Combustion Science, vol. 37, no. 4, pp. 371-421, 2011.

[69] K. Zhang et al., "An experimental and kinetic modeling study of the oxidation of hexane isomers: Developing consistent reaction rate rules for alkanes," Combustion and Flame, vol. 206, pp. 123-137, 2019.

[70] N. Atef et al., "A comprehensive iso-octane combustion model with improved thermochemistry and chemical kinetics," Combustion and Flame, vol. 178, pp. 111-134, 2017.

[71] S. M. Villano, L. K. Huynh, H.-H. Carstensen, and A. M. Dean, "High-pressure rate rules for alkyl+ $\mathrm{O} 2$ reactions. 2. The isomerization, cyclic ether formation, and $\beta$-scission reactions of hydroperoxy alkyl radicals," The Journal of Physical Chemistry A, vol. 116, no. 21, pp. 50685089, 2012.

[72] S. Y. Mohamed et al., "Modeling ignition of a heptane isomer: improved thermodynamics, reaction pathways, kinetics, and rate rule optimizations for 2-methylhexane," The Journal of Physical Chemistry A, vol. 120, no. 14, pp. 2201-2217, 2016.

[73] A. Miyoshi, "Systematic computational study on the unimolecular reactions of alkylperoxy (RO2), hydroperoxyalkyl (QOOH), and hydroperoxyalkylperoxy $(\mathrm{O} 2 \mathrm{QOOH})$ radicals," The Journal of Physical Chemistry A, vol. 115, no. 15, pp. 3301-3325, 2011. 
[74] Z. Wang and S. M. Sarathy, "Third O 2 addition reactions promote the low-temperature autoignition of n-alkanes," Combustion and Flame, vol. 165, pp. 364-372, 2016.

[75] H. J. Curran, P. Gaffuri, W. J. Pitz, and C. K. Westbrook, "A comprehensive modeling study of n-heptane oxidation," Combustion and flame, vol. 114, no. 1, pp. 149-177, 1998.

[76] H. J. Curran, P. Gaffuri, W. Pitz, and C. K. Westbrook, "A comprehensive modeling study of iso-octane oxidation," Combustion and flame, vol. 129, no. 3, pp. 253-280, 2002.

[77] Z. Wang et al., "Additional chain-branching pathways in the low-temperature oxidation of branched alkanes," Combustion and Flame, vol. 164, pp. 386-396, 2016.

[78] D. M. Manias, D. J. Diamantis, and D. A. Goussis, "Algorithmic Identification of the Reactions Related to the Initial Development of the Time Scale That Characterizes CH 4/Air Autoignition," Journal of Energy Engineering, vol. 141, no. 2, p. C4014015, 2014.

[79] D. Diamantis, D. Kyritsis, and D. A. Goussis, "Two stage ignition of n-heptane: identifying the chemistry setting the explosive time scales," in 2nd Intl. Conference in Model Reduction in Reacting Flows, 2009.

[80] J. A. Miller, M. J. Pilling, and J. Troe, "Unravelling combustion mechanisms through a quantitative understanding of elementary reactions," Proceedings of the Combustion Institute, vol. 30, no. 1, pp. 43-88, 2005. 